\title{
Psych verbs, the Linking Problem, and the Acquisition of Language
}

\author{
Joshua K. Hartshorne ${ }^{1,2}$ \\ Timothy J. O'Donnel1 ${ }^{1,2}$ \\ Yasutada Sudo ${ }^{3}$ \\ Miki Uruwashi ${ }^{2}$ \\ Miseon Lee ${ }^{4}$ \\ Jesse Snedeker ${ }^{2}$ \\ ${ }^{1}$ Department of Brain and Cognitive Sciences, Massachusetts Institute of Technology \\ ${ }^{2}$ Department of Psychology, Harvard University \\ ${ }^{3}$ Department of Linguistics and Philosophy, Massachusetts Institute of Technology \\ ${ }^{4}$ Department of English Language and Literature, Hanyan University, Korea
}

Running Title: Linking meaning to language

Send Correspondence to

Joshua Hartshorne

Massachusetts Institute of Technology

77 Massachusetts Avenue

46-4053H

Cambridge, MA 02139

Email: jkhartshorne@gmail.com

Tel: $617-253-3816$

\section{Acknowledgements:}

This work was presented at CogSci 2010 and BUCLD 2013, and benefited from comments. The authors additionally thank Amanda Pogue, Tanya Ivonchyk, Chen Chen, Dan Tassone, Allison Song, Maria Blokh, Yelyzaveta Ryabkina, and Yunqian Wang for assistance with translation and data-collection, Yi Ching Su for generous help with testing in Taiwan, Steve Piantadosi for statistical consultation, David Pesetsky for comments, and NDSEG (JKH), NSF GRFP (JKH), NIH NRSA 5F32HD072748 (JKH), the Allport Memorial Fund (JKH), and NSF 0921012 (JS) for funding. Stimuli and data for all studies can be found at osf.io/7ktp4. 


\section{Abstract}

In acquiring language, children must learn to appropriately place the different participants of an event (e.g., causal agent, affected entity) into the correct syntactic positions (e.g., subject, object) so that listeners will know who did what to whom. While many of these mappings can be characterized by broad generalizations, both within and across languages (e.g., semantic agents tend to be mapped onto syntactic subjects), not all verbs fit neatly into these generalizations. One particularly striking example is verbs of psychological state: The experiencer of the state can appear as either the subject (Agnes fears/hates/loves Bartholomew) or the direct object (Agnes frightens/angers/delights

Bartholomew). The present studies explore whether this apparent variability in subject/object mapping may actually result from differences in these verbs' underlying meanings. Specifically, we suggest that verbs like fear describe a habitual attitude towards some entity whereas verbs like frighten describe an externally caused emotional episode. We find that this distinction systematically characterizes verbs in English, Mandarin, and Korean. This pattern is generalized to novel verbs by adults in English, Japanese, and Russian, and even by English-speaking children who are just beginning to acquire psych verbs. This results support a broad role for systematic mappings between semantics and syntax in language acquisition.

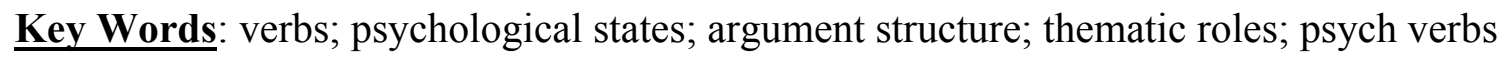
17,289 words, including captions and tables. 
In learning a language, a child must discover how the different participants in an event are expressed in the sentences that she hears. Otherwise, she'll never be able to explain whether the dog licked her brother (dull) or her brother licked the dog (tattleworthy). Languages signal these roles in a variety of ways including word order, case marking, and grammatical markers on the verb (Dryer \& Haspelmath, 2013), and thus solving this linking problem necessarily requires learning. But theories of language acquisition differ in their claims about how much is learned and how learning proceeds. A central distinction is between theories which begin with lexically-based generalizations and move toward greater abstraction (Goldberg, 1995, 2006; Tomasello, 1992, 2003; for review see Ambridge \& Lieven, in press, 2011) and theories which invoke broad, abstract links between syntactic and semantic representations from the beginning of language development (Gleitman, 1990; Grimshaw, 1981; Pinker, 1984, 1989).

The relative effectiveness of these two learning strategies depends on what exactly it is that children must learn. One possibility is that human languages are characterized by broad mappings between syntactic roles and semantic roles that apply across predicates of many kinds and which are subject to few if any exceptions (the systematic mappings hypothesis). If this is the case, then the learner will benefit from representing sentences in terms of these broad semantic and syntactic roles because doing so will allow her to exploit these mappings to make inferences from meaning to form and from form to meaning. In particular, systematic mappings support syntactic boostrapping, a process by which children use information about syntax to learn word meanings (Fisher, Gertner, Scott, \& Yuan, 2010; Gleitman, 1990; Gleitman, Cassidy, Papafragou, Nappa, \& Trueswell, 2005). For example, if a child knows that the subject of a transitive sentence is typically the actor and the object is typically the patient, then she can infer from hearing The boy gorped the dog that the new verb must describe the action performed by the boy upon the dog (e.g., petted or fed), rather an action performed by the dog on the boy (e.g., nuzzled or begged). Such regularities are also necessary for semantic boostrapping, a learning 
procedure where children use their knowledge of meaning to identify how syntactic functions are marked in their language (Grimshaw, 1981; Pinker, 1984, 1989). For example, if a child knows that agents of caused motion must be realized as the subject of a sentence, she can learn that English marks subjects with word order, that Russian uses inflectional morphology, or that Japanese uses particles, simply by paying attention to how causal agents are marked in the sentences she hears. Critically, on theories like these, broad linking rules are present in languages because every generation of children imposes these kinds of categories on events and sentences (see e.g., Gleitman \& Newport, 1995).

In contrast, if linking patterns are arbitrary historical conventions that vary across languages, apply to small sets of verbs, and admit many exceptions, then the strategy above will be counterproductive. Instead, it would be wiser for the child to take a conservative, bottom-up approach to generalization, like those proposed in constructivist theories (e.g., Goldberg, 1995, 2006; Tomasello, 2003). For example, on Tomasello's verb island hypothesis (1992), children initially analyze each predicate as an isolated grammatical island with open argument positions that can be filled with nouns. As more of these lexically-anchored constructions are acquired, children begin to notice the overlap in the semantic functions that are assigned to these fillers, as well as the overlap in their syntactic features (e.g., morphological marking or position relative to the verb). These observations lead them to form broader semantic categories (such as agent and theme), broader syntactic categories (such as verb, subject and object), and generalizations about the relationships between syntax and semantics.

Critically, on both theories adults (and older children) may have broad mappings between syntax and semantics, but the pathway by which they arrive at them is different, as is the degree of systematicity that would be expected both within and across languages.

\section{Are Mappings Systematic?}

Thus a critical question is whether languages are characterized by broad mappings with few, if any, exceptions (the systematic mappings hypothesis). To be precise, the controversy is about the degree 
of systematicity, not its existence. All theorists recognize that some of the syntax-semantics mappings are systematic. For example, in English and many other languages, an agent who causes motion or a change of state in another object is expressed as the subject of an active transitive sentence, rather than the object, regardless of the type of action (Baker, 1988; Croft, 2012; Dowty, 1991; Levin \& Rappaport Hovav, 2005; Tenny, 1994). Thus the breaker is the subject of break, the drier is the subject of $d r y$, the thrower is the subject of throw and the liquidator is the subject of liquidate. Both adults and toddlers readily extend this pattern to new verbs showing that, for these kinds of events, abstract mapping shapes early acquisition (Dittmar, Abbot-Smith, Lieven \& Tomasello, 2011; Fernandes, Marcus, Di Nubila \& Vouloumanos, 2006; Fisher \& Song, 2006; Kline \& Demuth, 2014; Marantz, 1982; Noble, Rowland \& Pine, 2011).

The mappings for other kinds events, however, are more controversial, harder to characterize, and arguably more variable both across predicates and across languages (Croft, 2012; Goldberg, 1995; Levin \& Rappaport-Hovav, 2005). Many verbs with closely related meanings appear to be governed by different linking rules: Agnes’s terror of Beatrice might be described with Agnes as the subject (Agnes feared Beatrice) or as the direct object (Beatrice frightened Agnes). An object moving from Agnes's possession to Beatrice's might be described as Agnes threw the ball to Beatrice or as Agnes threw Beatrice the ball. A single moment in a game of tag could be described as Agnes chased Beatrice or Beatrice fled from Agnes.

Taken at face value, such examples call into question the prevalence of broad, systematic mappings from semantics to syntax and the utility of learning procedures that seek to exploit such systematicity (cf. Bowerman, 1988; Braine \& Brooks, 1995; Boyd \& Goldberg, 2011; Goldberg, 2013). In fact, constructivist theorists have argued that, to acquire this complex mosaic of overlapping and conflicting linking patterns, a learner must begin at the bottom, learning the linking patterns item-byitem and gradually extending them on the basis of the input (Goldberg 1995, 2006, 2013; Tomasello, 
2003). Three lines of evidence lend credence to this account. First, lexically-anchored learning is clearly possible: languages contain idioms and other exceptional mappings (Jackendoff, 2002) and adults readily learn lexically-determined mappings in artificial language studies (Wonnacott, Newport, \& Tanenhaus, 2008). Second, in some natural language studies, young children are less likely than older children to generalize novel verbs from one construction to another (see e.g., Akhtar \& Tomasello, 1997; Brooks \& Tomasello, 1999; Dittmar et al., 2008; Tomasello, 2000), a pattern that is consistent with the claim that syntax-semantics mappings become more abstract over time (but see Fisher, 2000; Kline \& Demuth, 2014). Finally, both adults and older children can quickly learn an arbitrary syntaxsemantics mapping (one that is unattested in any known language) and generalize it to new verbs (Goldberg, Casenhiser, Sethuraman, 2004; Casenhiser \& Goldberg, 2005), while under these same circumstances five-year olds will only acquire lexically-anchored mappings (Boyd \& Goldberg, 2012).

In this paper, we explore a different explanation for these apparent cases of ambiguity and conflict in the linking rules (e.g., chase/flee, fear/frighten). Perhaps the principles that link semantic arguments in an event to syntactic positions in a sentence are broad and fully consistent, but we as scientists sometimes fail to see these patterns because we have not correctly characterized the semantic structure. Above we tacitly assumed that if two sentences could refer to the same event, then they had the same semantics, but this assumption is clearly false. Just as the words dog, canine, pet and carnivore may all be used to refer to the same animal while nonetheless maintaining distinct meanings, sentences may describe the same event while nonetheless picking out different construals - or conceptualizations of the event (Gentner \& Boroditsky, 2001; Gleitman, 1990; Gleitman et al., 2005).

For example, above we noted that in English there are two syntactic structures that are used to describe transfer events:

(1) a. Agnes threw/kicked/mailed/shipped the ball to Darpny. (prepositional dative) b. Agnes threw/kicked/mailed/shipped Darpny the ball. (double-object dative) 
While these two forms are often used to describe similar events, they are argued to express different meanings (Beavers, 2011; Gropen, Pinker, Hollander, Goldberg \& Wilson, 1989; Harley, 2002; Mazurkewich \& White, 1984; Oehrle, 1976; Rappaport Hovav \& Levin, 2008). For example, in (1b) Darpny must be a person or organization that is capable of possession, while in (1a) Darpny could simply be a location to which the ball has been sent. This observation has led many theorists to conclude that the two dative constructions express two different semantic structures, or conceptualizations, of transfer events, which are mapped onto two different syntactic forms (Harley 2002; Rappaport Hovav \& Levin, 2008; Beavers, 2011; Pinker, 1989). Specifically, the to dative in (1a) specifies change of location, whereas the double-object data (1b) specifies change of possession. Critically, if the two dative structures have different underlying semantics, they are no longer a problem for the systematic mappings hypothesis.

Arguments like this one allow us to preserve the systematic mappings hypothesis. However, before we can use them to ground our theory of acquisition, we need three kinds of evidence. First, we need evidence of systematicity: proof that the rule applies to most or all sentences with the relevant semantics. Second, we need evidence of generalization: proof that adults can extend the rule to novel items, demonstrating that individuals represent the rule and can use it productively. Finally, to show that the rule could play a role in language development, we need evidence of early emergence: proof that children know the linking rule and extend it to new items early enough to make use of it during language acquisition. How early the rule emerges will determine precisely what role it can play in language development.

In the case of the dative alternation (see above) we are well on our way to meeting these challenges. We know that adults' use of novel transfer verb in the double object and to dative depends upon its meaning and that this ability is present by five years of age (Ambridge, Pine, Rowland, \& 
Chang, 2012; Gropen et al., 1989). ${ }^{1}$ Thus this subtle distinction in meaning could play a substantial role in acquiring dative verbs. Similar evidence has been marshaled for several other cases, including locative alternation (Ambridge, Pine, \& Rowland, 2012; Gropen, Pinker, Hollander, \& Goldberg, 1991a, 1991b), where there is evidence of generalization in preschoolers, and causal transitive-intransitive alternations (Ambridge, Pine, \& Rowland, 2011; Ambridge, Pine, Rowland, \& Young, 2008; Kline \& Demuth, 2014), where there is evidence of generalization in children as young as $2 ; 6$.

While compelling, these cases are just a few of the many challenges to the systematic mapping hypothesis. The dative, locative, and causal alternations are only three of dozens of such patterns, including the middle, benefactive, uspecified object, and conative alternations (Levin, 1993). There are thousands of examples of verbs that have similar meanings but appear in different syntactic constructions in addition to the examples given above (e.g., Agnes conned $\$ 20$ from Beatrice vs. *Agnes cheated \$20 from Beatrice). In many cases where mappings appear to be inconsistent, linguists have suggested potential semantic solutions (cf. Levin \& Rappaport Hovav, 2005). But in most of these cases we have little or no information about systematicity, generalization or early emergence, much less all three. If we wish to rigorously test the systematic mappings hypothesis, we will ultimately need experimental work on each of these proposals.

The present study begins that process by taking on what has been arguably been the most stubborn example of apparent inconsistency in linking rules: psych verbs. If these verbs can be reconciled with the systematic mappings hypothesis, it would suggest that other cases could be reconciled as well. If they cannot be reconciled, it would put an upper limit on just how systematic child learners can expect languages to be.

\section{Psych verbs}

\footnotetext{
${ }^{1}$ Ambridge and colleagues (2012) do not report the relevant analyses, but they can be reconstructed from the tables. Children ages 5-6, children ages 9-10, and adults all judged novel verbs in double-object constructions as better if the verbs denoted change of ownership than if they did not, after controlling for plausibility of the verb itself, which was rated by a separate set of adults. The results were reported by item rather than by subject, and there are too few items to do significance analyses, but the effect sizes for the children are respectable: a Cohen's d of 0.2 for the 5-6 year-olds and 0.5 for the 9-10 year-olds.
} 
As noted above, in English and many other languages, some verbs of emotion map the experiencer of the emotion onto the subject and the stimulus onto the object (fear-type verbs: Agnes feared/hated/loved Bartholomew), while others follow the reverse pattern (frighten-type verbs: Agnes frightened/angered/delighted Bartholomew) (Belletti \& Rizzi, 1988; Bialy, 2005; Croft, 1993, 2013; Dowty, 1991; Landau, 2010; Levin, 1993; Pesetsky, 1995; Pylkkanen, 1999). ${ }^{2}$ Not only do both classes of verbs describe emotions, they describe the same types of emotions. We confirmed this in two preliminary studies in which we asked naïve participants to classify fear-type and frighten-type verbs according to the two most widely-accepted theories: Ekman's (1992) basic emotions theory and the Valence-Arousal model (Russell, 1980). By either measure, both frighten-type and fear-type verbs describe a broad and overlapping range of emotions (Table 1; Figure 1). Thus, at least at first glance, psych verbs appear to involve a non-systematic mapping from semantics to syntax.

There have been many attempts to distinguish fear-type and frighten-type verbs semantically and thus reconcile them with the systematic mappings hypothesis. There appear to be relatively few true doublets in English (like fear/frighten or like/please), which raises the possibility that there is something systematically different about emotional states that are encoded in the two types of verbs. However, there is no clear consensus about what the relevant semantic distinction is or how it explains the linking patterns. Many authors invoke the notion of causality, but they disagree about how it applies. Tenny (1995) argues that the stimulus of frighten-type verbs (e.g., Agnes in Agnes frightened Bartholomew) is the cause of the emotion, whereas the stimulus in fear-type verbs is not (see also Grimshaw, 1990; Talmy, 1985; Pesetsky, 1995). This claim is disputed by Dowty (1991), who argues that the stimulus is always causal (see also Rozwadowska, 1992). Croft (2012) agrees that the stimulus of frighten-type verbs is causal, but argues that the experiencer of fear-type verbs is causal as well. This is because frighten-type verbs highlight the causal role of the stimulus (causing a change of mental state) whereas

\footnotetext{
${ }^{2}$ In many languages, there are also affect verbs that require oblique cases (Agnes worried about/mattered to Bartholomew). Because far less is known about these verbs, we did not include them in this initial investigation.
} 
fear-type verbs highlight the causal role of the experiencer (directing her mental attention to the stimulus) (see also Jackendoff, 1990). Talmy (1995) agrees with this intuition, but argues that this is a form of semantic illusion resulting from the typical linking patterns ("subjecthood, perhaps because of its frequent association with agency, may tend to confer upon any semantic category expressed in it some initiatory or instigative characteristics"; p. 101). Because this illusion is a downstream effect of linking, it cannot explain the variation in linking patterns. Landau (2010) stakes out a slightly different position where many frighten-type verbs but no fear-type verbs can be agentive. However, agentivity cannot entirely explain the fear/frighten distinction, since some frighten-type verbs are non-agentive.

Table 1. English psych verbs in each basic emotion category

\begin{tabular}{lllll}
\hline Basic Emotion & & Fear-type & & \multicolumn{2}{l}{ Frighten-type } & P-value \\
\cline { 2 - 2 } Anger & 5 & & 19 & .58 \\
Awe & 4 & 11 & .27 \\
Contempt & 1 & 2 & .07 \\
Disgust & 1 & 0 & .33 \\
Embarrassment & 1 & 4 & .59 \\
Enjoyment & 8 & 20 & .12 \\
Excitement & 1 & 13 & .71 \\
Fear & 1 & 9 & 1.0 \\
Guilt & 0 & 0 & $\mathrm{NA}$ \\
Interest & 1 & 12 & .71 \\
Sadness & 0 & 12 & .24 \\
Shame & 0 & 2 & 1.0 \\
Surprise & 2 & 7 & .65 \\
Other & 1 & 4 & .59
\end{tabular}

Ten native English speakers classified 42 fear-type and 216 frighten-type verbs from Levin (1993) into the thirteen basic emotions listed by Ekman (1992), plus the category of "other". Note that we glossed his positive emotion category ("amusement, relief, sensory pleasure, pride in achievement, the thrill of excitement, satisfaction, and contentment"; Ekman, 1992, p. 190) as "enjoyment". Of the 141 verbs that could be classified, the ratio of each emotion type was indistinguishable from the ratio in the language as a whole (approx. 16\% fear-type). 


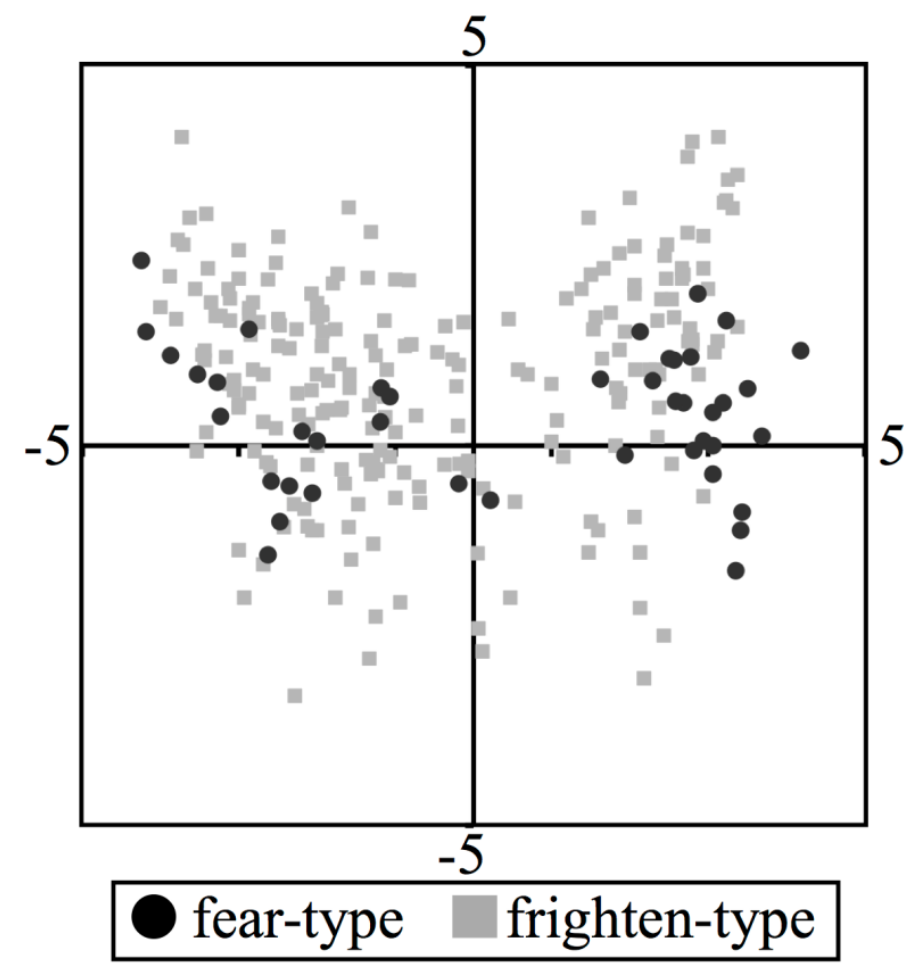

Figure 1. Valence (x-axis) and arousal (y-axis) for 42 fear-type and 216 frighten-type verbs listed in Levin (1993), rated by 18 naïve participants on 11-point Likert scales (negative-positive, asleepexcited).

Other theorists have explored aspectual (temporal) distinctions between the two classes of verbs. Here there is a broad consensus that fear-type verbs describe static states whereas frighten-type verbs can describe events. In other words, Agnes frightened Bartholomew can entail that Bartholomew became afraid, but Bartholomew fears Agnes cannot (Dowty, 1991; Croft, 1986; Tenny, 1994). This distinction, however, cannot fully explain the linking patterns, because frighten-type verbs can also have stative readings. Arad (1998) and Landau (2010) propose that this variation is attributable to systematic differences between different classes of frighten-type verbs (e.g., concern is necessarily stative), while Grafmiller (2013) argues that this variation is probabilistic and based on world knowledge and the contexts in which the verbs are used. But critically, on either proposal, the distinction between events and states cannot account for the difference in linking patterns, since stative frighten-type verbs pattern like eventive frighten-type verbs. Pylkkanen (1999) addresses this challenge directly, suggesting that 
while some frighten-type verbs are states and others are events, all frighten-type verbs describe emotional states that can be bound to a time and place (Agnes concerned Bartholomew yesterday in the kitchen), whereas no fear-type verbs do (*Agnes feared Bartholomew yesterday in the kitchen). ${ }^{3}$

Other researchers point to yet other constructs. For instance, Pesetsky (1995), in addition to arguing that frighten-type verbs are causal, notes that the stimulus of fear-type verbs must also be the target: If Agnes hated the newspaper article, her rage was directed at the article itself. In contrast, the stimulus of frighten-type verbs need not be the target of the emotion: The newspaper article angered Agnes can be true even when she is not angry at the article itself - she may actually think it is investigative journalism of the finest sort.

Finally, yet other theorists maintain that the linking patterns for some (or all) psych verbs are arbitrary and must be learned (Belletti \& Rizzi, 1988; Bowerman, 1988; Culicover \& Jackendoff, 2005; see also Pinker, 1984). For example, Cullicover and Jackendoff (2005), who generally advocate a semantics-based approach to linking, despair of finding such an analysis of psych verbs: "There have been attempts to demonstrate a consistent semantic difference associated with these configurations (e.g., Grimshaw, 1990; Pesetsky, 1995), but we find them unpersuasive when one considers the full range of predicates" (p. 184), and thus "linking has to be specially stipulated by either experiencer-subject verbs (regard, enjoy, like) or experiencer-object verbs (strike, please, appeal to) or both” (p. 215).

Thus, while many theorists agree that there is some semantic distinction, not all do, and even those who posit a semantic distinction disagree about what that distinction is. Moreover, they disagree about what type of semantic distinction would be relevant: Dowty's semantic analysis - but not Grimshaw's or Croft's - correctly predicts the linking pattern of the two classes under his theory of linking. Consequently, it is far from clear that we can predict the linking patterns of psych verb from their semantics.

\footnotetext{
${ }^{3}$ Formally, she argues that frighten-type verbs are stage-level predicates whereas fear-type verbs are individual-level predicates (Carlson, 1977).
} 
While there has been experimental work on psych verbs, these studies have focused largely on the kinds of errors that participants make when comprehending and producing fear and frighten verbs. As such, this work does not provide direct evidence for or against the systematic mappings hypothesis. Both learners of second languages and patients with agrammatic aphasia make more errors with frighten-type verbs than fear-type verbs (Chen, 1996; Montrul, 2001; Pinango, 2000; Sato, 2003; Thompson \& Lee, 2009; White, Brown, Bruhn-Garavito, Chen, Hirakawa, \& Montrul, 1998). While these findings are consistent with the suggestion that frighten-type verbs are exceptions to a general rule linking experiencers to subject position, they are open to a variety of other interpretations (see General Discussion). Furthermore, any claim that fear-type verbs follow a default rule while frighten-type verbs are exceptions would be hard to reconcile with recent finding that children learn frighten-type verbs earlier, despite the fact that they tend to be lower-frequency than fear-type verbs (Hartshorne, Pogue, \& Snedeker, in press).

In summary, there is no clear consensus about whether there $i s$ a semantic distinction between the fear-type verbs and frighten-type verbs or what that distinction might be. Thus psych verbs are a critical test case for the systematic mappings hypothesis, because they appear to be the strongest example of unexplained variability in the linking rules. If they cannot be resolved through careful semantic analysis, that would put an upper bound on just how systematic linking can be. In contrast, if a semantic resolution can be found, that would not only remove a major hurdle for the systematic mappings hypothesis (that is, accounting for psych verbs) but it would also suggest that other cases may be similarly resolved.

\section{Overview of the Experiments}

Below, we test whether the dueling linking patterns exhibited by fear-type and frighten-type verbs can be explained by different underlying semantics. In particular, we suggest that fear-type verbs describe an experiencer having a particular attitude about some target, whereas frighten-type verbs 
describe a specific instance in which a person (or event) elicited a particular emotion in an experiencer. Thus, Agnes feared Bartholomew means that Agnes generally had a fearful attitude towards Bartholomew, whereas Bartholomew frightened Agnes means that Bartholomew caused Agnes to feel fright at some specific time and place. ${ }^{4}$ This characterization is reminiscent of a distinction frequently made in the affective processing literature between habitual attitudes (fear) and emotional episodes (frighten) (cf. Ekman, 1992).

This analysis shares aspects of several of the accounts described in the previous section. First, it incorporates Pesetsky's claim (1995) that frighten-type verbs describe the cause of a mental state but do not directly encode the content (the target), while fear-type verbs encode the content but not the cause. Thus the non-experiencer roles are different for the two classes of verbs. Second, by distinguishing between habitual attitudes and emotional episodes, our account is similar to those that distinguish between states and events (Dowty, 1991; Croft, 1986; Tenny, 1994) or between unbounded and bounded states (Pylkkanen, 1999).

As noted above, both fear-type and frighten-type verbs are both found in a wide range of languages, a fact which itself needs explanation. We suggest that this is because these two conceptualizations of emotional episodes are shared broadly across individuals and cultures. As a result, in many languages, there are psych verbs lexicalizing each of these conceptualizations. Within a language, both classes of verbs are subject to the same set of linking rules, but the difference in the underlying semantic structure results in different patterns of argument realization (see General Discussion). To test this hypothesis, we investigate the proposed analysis of psych verbs in a variety of languages.

We test our analysis of psych verbs as follows. First, we show that fear-type and frighten-type

\footnotetext{
${ }^{4}$ Because the temporal properties of a sentence are frequently an interaction of verb, aspect, adverbials, etc. (Moens \& Steedman, 1988), in some contexts the event/habit distinction may be obscured. For instance, the English present tense can be used to describe habitual events [Bartholomew fails exams (always)]. Thus, even if Bartholomew frightened Agnes refers to a single event, Bartholomew frightens Agnes can describe a habitual event somewhat analogous to Agnes fears Bartholomew. This is not expected to affect other semantic distinctions between the verb types, such as encoding of causality. We compare present and past tense in Exps. 5-8.
} 
verbs can indeed be systematically distinguished semantically in English, Mandarin, and Korean along the dimensions described above (evidence of systematicity). Then, we show that adult speakers of multiple languages (English, Japanese, and Russian) apply these patterns to novel verbs (evidence of generalization). Finally, we show that children just beginning to acquire psych verbs in English already generalize this pattern to new verbs, showing that it has an active role to play in guiding early learning (evidence of early emergence). Stimuli and raw data for all studies are available at https://publicdata.bc.edu/projects/LAT/repos/hartshorneodonnelletal_cognition_psychverbs/.

\section{Experiments 1-4: Systematicity}

As described in the previous section, our proposed semantic analysis distinguishes fear-type and frighten-type verbs along multiple dimensions. In this section, we test two of these distinctions: the claim that fear-type verbs describe habitual attitudes whereas frighten-type verbs describe specific episodes of emotion (Exp. 1), and the claim that frighten-type verbs encode causality but fear-type verbs do not (Exps. 2-4).

\section{Experiment 1: Attitudes and Emotions (English)}

Above, we argued that while frighten-type verbs describe a specific instance in which an emotional state occurs (The bats swooped out of the cave and frightened Agnes), fear-type verbs do not (*The bats swooped out of the cave and Agnes feared them). However, it is critical to show that naïve participants share this intuition, and that this intuition extends to a comprehensive set of psych verbs.

In Exp. 1, we asked naïve participants to classify the 42 fear-type and 216 frighten-type verbs listed in Levin's (1993) comprehensive list of psych verbs. However, rather than try to train participants to distinguish attitudes from emotions, we asked them to make a correlated but much more natural judgment: How long is the mental state associated with each verb likely to last? While, in principle, an emotional episode could potentially last a long time (Agnes remained frightened for years), and a habitual attitude could change rapidly (Agnes only feared Bartholomew for a little while, until she got to 
know him better), on average the former will last a shorter time than the latter.

Method. Forty-eight native English-speaking adults, ages 19-77 ( $\mathrm{M}=38, \mathrm{SD}=14)$, were recruited and tested through an Internet experiment portal (gameswithwords.org). Additional participants, who were not native English speakers, did not complete the experiment, or who were under 18 years old, were excluded.

Participants were given sentences like "Sally frightened Mary" and asked to rate how long the mental state was likely to have lasted: seconds, minutes, hours, days, weeks, months, or years. We tested 42 fear-type and 216 frighten-type verbs listed in Levin (1993). The order of verbs was randomized for each participant. In order that participants did not build biases about the people mentioned in the stories, the names in each story were drawn randomly on each trial for each participant from a total of 70 names.

Results and Discussion. The participants' answers were converted to a 7-point Likert scale for analysis. Participants judged the mental state described in fear-type verbs to last significantly longer than those described by frighten-type verbs $(t(256)=19.9, p<.001)$ (Figure 2$) .18$ of the fear-type verbs (42\%) were judged to have longer durations than any of the frighten-type verbs, and 153 of the frightentype verbs (71\%) were judged to have shorter durations than any of the fear-type verbs.

This constitutes a very large effect - the amount of overlap is similar to that of two normal distributions separated by 2.6 standard deviations (for comparison, the difference between means in the typical psychology study is less than 0.5 standard deviations; Hartshorne \& Schachner, 2012). ${ }^{5}$ This is particularly striking given that, as discussed above, episodes are only probabilistically shorter in duration than habits and attitudes.

\footnotetext{
${ }^{5}$ In 10,000 simulations involving two normal distributions separated by 2.6 SDs, the median percentage of fear-type verbs judged to be longer than any frighten-type verbs was $45 \%$, whereas the median percentage of frighten-type verbs judged to be shorter than any fear-type verbs was $68 \%$.
} 


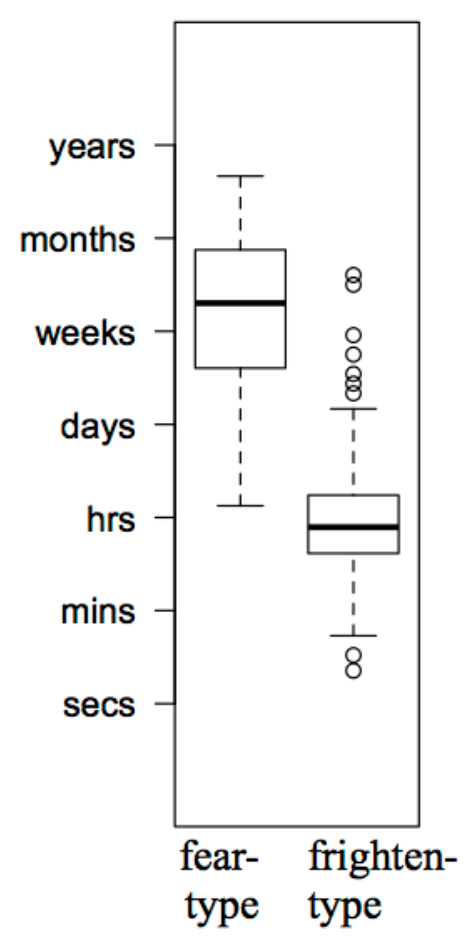

Figure 2. Results of duration ratings by verb in Exp. 1. Error bars represent 1.5 standard deviations.

These results also have some bearing on a recent debate about whether some frighten-type verbs are stative (Arad, 1998; Grafmiller, 2013; Landau, 2010). In this literature, the inability to appear in the present progressive is often taken as a test for stativity (*John is knowing the answer) and thus the fact that some frighten-type verbs are less natural in the present progressive (e.g., The situation is depressing Agnes) is seen as evidence that these verbs are stative. Grafmiller (2013) argues that acceptability in the progressive is a pragmatic effect: The present progressive describes a temporary situation, which is thus odd for relatively durable states (compare: *The house is standing at the end of Longfellow Place vs. The mobile home is standing at the end of Longfellow Place). In a detailed study of 16 frighten-type verbs, Grafmiller finds that they vary in the expected duration of the event and that this is reflected in how acceptable the verbs are in the present progressive. Our data provide some indirect support for this analysis. Though the emotions described by most frighten-type verbs were expected to be short in duration, some were judged to last longer. In fact, the four verbs that are most consistently hypothesized 
to be stative (bore, concern, depress, worry; cf. Grafmiller, 2013) were judged as having an average duration that is longer than the other frighten verbs (3.7 vs. 2.9 on the 7-point Likert scale) but shorter than the average fear-type verb (5.2).

Note that from our data alone, we cannot determine whether the relationship between syntax and semantics is merely very strong (most fear-type verbs describe habitual attitudes and most frighten-type verbs describe emotional episodes) or categorical (all fear-type verbs describe habitual attitudes and all frighten-type verbs describe emotional episodes). The slight overlap in the ratings for the two verb-types could be due to exceptions in the pattern, to noise and measurement error, or to both. ${ }^{6}$ Because none of the theories we are investigating require or predict exceptionless linking patterns, we leave the project of carefully delineating the semantics of each psych verb to future.

\section{Experiment 2: Causation (English)}

On our semantic analysis, frighten-type verbs describe situations where the stimulus caused the mental state, whereas fear-type verbs do not encode causation (cf. Grimshaw, 1990; Pesetsky, 1995). We presented naïve participants with psych verb sentences (Agnes frightened Bartholomew) and asked them to determine who, if anyone, caused the mental state. We predicted that for frighten-type verbs, participants would systematically select the subject (stimulus), whereas for fear-type verbs, participants would not have a strong or consistent preference.

Method. Participants were 20 English-speakers ages 24-41 (M=30, SD=5) who were recruited through the university study pool and were compensated with course credit or a small payment. Additional participants who did not complete the test or were not native speakers of English were excluded. Stimuli consisted of 42 fear-type and 216 frighten-type verbs listed in Levin's (1993) comprehensive survey.

In order to get crisp judgments about causality, we presented adult participants with a court case

\footnotetext{
${ }^{6}$ One might think that a categorical distinction in the grammar would always result in a categorical distinction in the participants data. However, assuming Gaussian noise with standard deviation $s$, even if the true expected durations of fear-type and frighten-type events were categorically separated by $5 * s$, the experimenter has a better than $25 \%$ chance of observing some overlap.
} 
scenario in a science fiction context in which it is illegal to knowingly or negligently cause emotions in other people. Participants were presented with court cases such as "Mary frightened Sally," and asked whether anyone was guilty of causing an emotion. They were told that, "Sometimes emotions simply happen on their own," in which case, it is nobody's fault and nobody should be convicted. Stimuli were presented on a computer and the order of the verbs was randomized separately for each participant, as was which names went with which verbs (we used the 70 common female names used in Exp. 1).

Results and Discussion. As can be seen in Figure 3, Panel A, for frighten-type verbs, participants overwhelming assigned the subject (stimulus) causal responsibility, whereas for fear-type verbs, no single response dominated. For statistical comparison, verbs were labeled based on the answer given by the majority of the participants: the subject, the object, or neither. If there was no majority answer, that verb was labeled as "unclassifiable." The results for fear-type and frighten-type verbs were significantly different in a Fisher's Exact Test $(p<.001)$. Similar results were obtained when the verbs were labeled according to whether the cause was the stimulus, experiencer, or neither. The results for fear-type and frighten-type verbs was again different $(p<.001)$.

The crucial question for the systematic mappings hypothesis is not whether this semantic distinction holds on average but whether it holds for most or all of the verbs. Thus, for each verb, we determined whether participants chose one of the responses significantly more often than the rest. Specifically, we calculated whether the most common response was significantly more common (in a binomial test) than the next most common response (in which case it was necessarily significantly more common than the least common response). ${ }^{7}$

These by-item analyses confirm the general pattern: Participants selected the subject (stimulus) more than either of the other answers for 214 of 216 frighten-type verbs, reaching statistical significance in 96 cases $(p s<.05)$. One frighten-type verb showed a non-significant preference for "neither" and one

\footnotetext{
${ }^{7}$ Alternatively, we could have asked whether one of the responses was more common than chance. However, for fear-type verbs, typically both the stimulus and "neither" were chosen at rates greater than chance for the simple reason that the experiencer was unlikely to be chosen. Thus, the crucial question was whether participants preferred the stimulus to "neither" or vice versa.
} 
was unclassifiable. In contrast, for fear-type verbs, only two verbs reached statistical significance, both of which showed a preference for subject. Nor did the non-significant biases of the remaining fear-type verbs reveal any systematic pattern: 18 leaned non-significantly towards the subject, 7 non-significantly towards the object, 5 non-significantly towards "neither", and 10 were unclassifiable.

Thus, as predicted, there was a sharp distinction between the frighten-type and fear-type verbs, with the former supporting clear intuitions about causality (the subject of the verb was causally responsible) and the latter not supporting any clear intuitions about causality. Note that participants did not necessarily judge that fear-type verbs have no cause; they merely appeared unsure as to what the cause was, exactly as predicted if fear-type verbs do not specify causality.

These results align with our proposed semantic analysis and with previous work by Grimshaw (1990) and Pesetsky (1995). They do not support Croft's (2012) and Talmy's (1995) suggestion that the subject is always causal, Dowty's (1991) and Rozwadowska's (1992) suggestion that the stimulus is always causal, nor Landau's (2010) argument that some frighten-type verbs are causal and others are not.

\section{Experiment 3: Causation (Mandarin)}

In addition to English, many other languages have both fear-type and frighten-type verbs. In Exp. 3, we asked whether the distinction in how the two types of verbs encode causality extended to Mandarin, a language unrelated to English.

Method. Participants were 44 Mandarin speakers ages 18-32 (M=20, SD=3) who were tested in a classroom setting in Taiwan and compensated with a souvenir. Additional participants who did not complete the test or were not native speakers of Mandarin were excluded. Stimuli consisted of 25 feartype and 25 frighten-type verbs in Mandarin, selected from a comprehensive list compiled by the authors.

The procedure followed that of Exp. 2 except as follows. The task was paper-and-pencil. As 
such, while the story participants varied across trials (a total of 90 names were used), which characters went with which verb was fixed. Four booklets were created, counter-balancing the order of verbs and which person in the story was the subject or object of the sentence.

Results and Discussion. As can be seen in Figure 3, Panel B, for frighten-type verbs, participants overwhelmingly assigned the subject (stimulus) causal responsibility, whereas for fear-type verbs, they were at least as likely to choose "neither" as any other answer. The difference between feartype and frighten-type verbs was significant in a Fisher's Exact Test $(p<.001)$. The difference was again significant when verbs were labeled according to whether the cause was the stimulus, experiencer, or neither $(p<.001)$.

Closer inspection of the results confirmed the general pattern. Participants selected the subject (stimulus) more than either of the other answers for 22 of 25 frighten-type verbs, reaching significance in 19 cases $(p s<.05)$. Two frighten-type verbs showed a non-significant preference for the object and one was unclassifiable. In contrast, only two fear-type verbs had significant biases (one for the subject, one for the object). Again, the fear-type verbs that did not reach significance did not reveal any systematic pattern: 8 leaned non-significantly towards the subject, 14 towards "neither", and 1 was unclassifiable.

Thus, as in English, Mandarin psych verbs exhibit a sharp distinction in the conclusions they license about causality, with frighten-type verbs typically indicating that the subject was causally responsible while fear-type verbs rarely license clear conclusions about causality. 

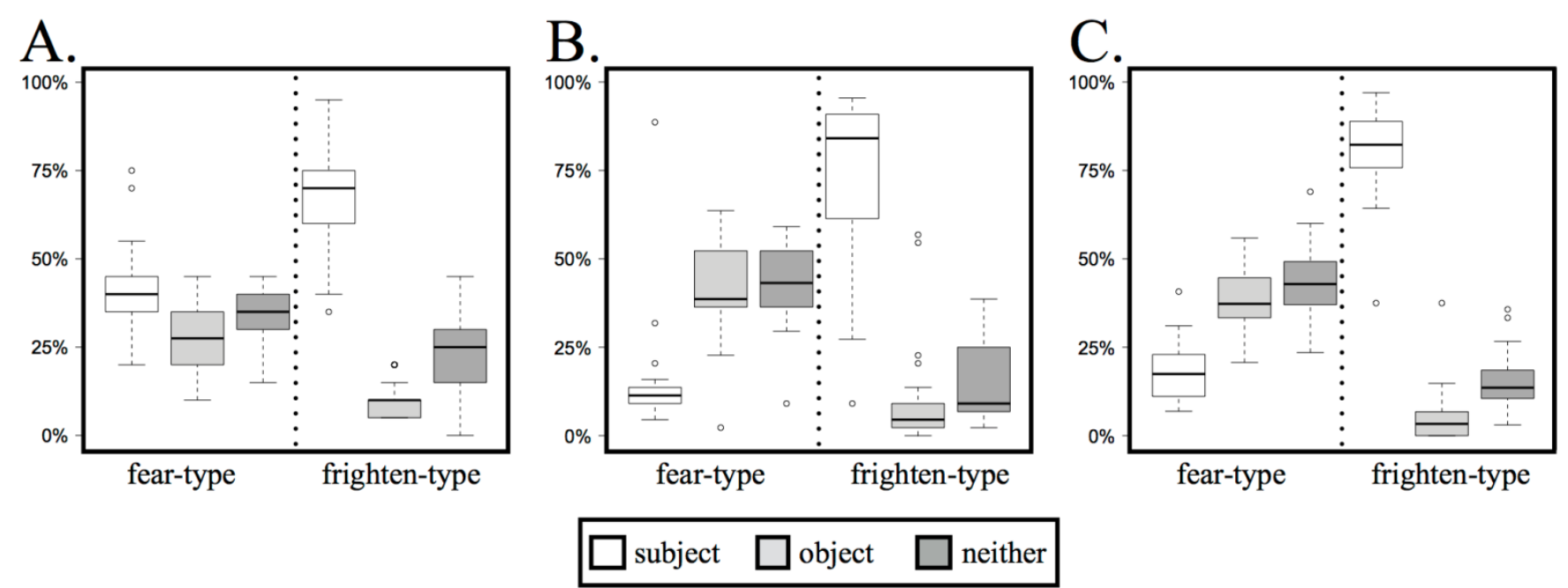

fear-type

frighten-type

Figure 3. The percentage of participants choosing each option, calculated by verb for English in Exp. 2 (Panel A), Mandarin in Exp. 3 (Panel B), and Korean in Exp. 4 (Panel C). Error bars represent 1.5 standard deviations.

\section{Experiment 4: Causation (Korean)}

In Exp. 4, we asked whether the distinction in how the two types of verbs encode causality that were observed for English and Mandarin extended to Korean, a language historically unrelated to either English or Mandarin.

Method. Participants were 34 Korean-speakers ages 24-41 (M=30, SD=5) who were recruited and tested online (http://www.gameswithwords.org/Korean/). Additional participants who did not complete the test, who were not native speakers of Korean, or who reported having already done the experiment were excluded. Stimuli consisted of 40 fear-type and 40 frighten-type verbs in Korean, compiled by the authors, as well as 10 fillers. All the Korean frighten-type verbs and half the fear-type verbs had subjects in nominative case and objects in accusative case. The remaining Korean fear-type verbs require both arguments to be in nominative case. The procedure was identical to that of Exp. 2 except that names on each trial were drawn from a total set of 100 instead of 70.

Results and Discussion. As can be seen in Figure 3, Panel B, for frighten-type verbs, 
participants overwhelmingly assigned the subject (stimulus) causal responsibility, whereas for fear-type verbs, they were as likely to choose "neither" as any other answer. The difference between fear-type and frighten-type verbs was significant in a Fisher's Exact Test $(p<.001)$. The difference was again significant when verbs were labeled according to whether the labeled cause was the stimulus, experiencer, or neither $(p<.001)$.

Again, closer inspection of the results confirmed the general pattern. Participants selected the subject (stimulus) significantly more often than either of the other answers for 39 of 40 frighten-type verbs, significantly so in 37 cases. One frighten-type verb was unclassifiable. In contrast, only one feartype verb had a significant bias (for "neither"). If there was any pattern among the non-significant biases for the remaining fear-type verbs, it was to choose "neither" (23 verbs), with non-significant biases for the object in 14 cases, the subject in one case, and two unclassifiable verbs.

Thus, as in English and Mandarin, Korean psych verbs exhibit a sharp distinction in the conclusions they license about causality, with frighten-type verbs typically indicating that the subject was causally responsible while fear-type verbs rarely license any conclusions about causality.

\section{Summary of Experiments 1-4 (Systematicity)}

In Exps. 1 \& 2, we conducted a nearly exhaustive survey of the transitive psych verbs in English (cf. Levin, 1993) and found that frighten-type verbs describe specific emotional episodes caused by the stimulus, whereas fear-type verbs describe habitual attitudes with no specific cause. We extended the findings for causation to Mandarin (Exp. 3) and Korean (Exp. 4), albeit with smaller sets of verbs. As detailed in the next section, in a number of languages such as Japanese and Finnish, frighten-type verbs are often marked with explicit causal morphology - a fact consistent with our findings for English, Mandarin, and Korean (cf. Pesetsky, 1995; Pylkkanen, 1999).

Our results are consistent with the systematic mappings hypothesis: If fear-type verbs and frighten-type verbs have categorically different meanings, then it is possible that a unitary set of linking 
rules can predict both patterns. However, this evidence is correlational. The correlation may play no role in the underlying linguistic representations of linking and may not be used in acquisition (cf. Braine \& Brooks, 1995, p. 364). It may even be a spurious relationship: If researchers consider enough semantic features, one is bound to correlate with the fear/frighten distinction, and, as we noted in the Introduction, many semantic features have been considered. The fact that the causation results replicate across several languages is suggestive, but not conclusive. We address these considerations in the next two sections.

\section{Experiments 5-8: Generalization}

Is the correlation between syntax and semantics demonstrated above a peculiar piece of trivia, or information that people utilize to represent and process language? The gold standard test is the "wug" test, which assesses whether individuals extend a linguistic pattern to novel items (Berko Gleason, 1958). In our case, this amounts to testing whether people use the semantic distinctions discussed above to determine whether a novel psych verb should follow fear-type syntax or frighten-type syntax. In Exps. 5-8, we manipulated whether novel psych verbs described habitual attitudes or emotional episodes, predicting that participants would assign fear-type syntax to the former and frighten-type syntax to the latter. We focused on manipulating the attitude/episode distinction rather than the encoding of causality, because it lent itself to a simple and yet subtle manipulation.

We investigated three languages: English (Exps. 5 \& 7), Japanese (Exp. 6), and Russian (Exp. 8). Japanese is of particular interest because causality is explicitly marked in the structure of Japanese frighten-type verbs by adding the causal affix - (s)ase- to fear-type verbs or other emotion words:

(2) a. Taro-wa koomori-o kowagat-ta.

Taro-TOPIC bat-ACC fear-PAST

Taro feared bats.

b. Koomori-wa Taro-o kowagar-ase-ta. bat-TOPIC Taro-ACC fear-CAUS-PAST 
Bats frightened Taro.

By our counts, all -(s)ase- affixed verbs are frighten-type, whereas approximately $94 \%$ of unaffixed verbs are fear-type. As a result, the - $(s)$ ase- affix is highly predictive of frighten-type or fear-type syntax. In contrast, morphology in English provides no cues (no English psych verbs are causativeaffixed, with the possible exception of frighten, which contains the archaic English causative affix -en).

Thus, Japanese morphology provides an extremely strong cue to the linking patterns for psych verbs, a cue that is absent in English. If Japanese speakers are nonetheless sensitive to semantics independent of affixation, it would suggest that semantics plays a role in linking rules even when there are morphological cues that might block a learner from acquiring this contingency or override any subtle correlation.

\section{Generalization in English: Experiment 5}

English-speakers were presented with novel "loan words" from Japanese for which there was no English equivalent. For each, they were given a forced-choice judgment between using the verb like a fear-type or frighten-type verb.

Method. Forty English-speaking participants participated: Twenty in Exp. 5a (18-60 y.o., M=25, $\mathrm{SD}=10)$ and twenty in Exp. 5b (18-39 y.o., $\mathrm{M}=23, \mathrm{SD}=5)$. Participants were recruited outdoors on Harvard's campus and compensated with a small gift.

We selected sixteen Japanese nouns that described psychological states for which there is no verb in English (cf. 3). These nouns were turned into verbs, applying any phonological accommodations necessary to make them pronounceable in English. Based on a description of the psychological state, participants were asked to choose between using the verb in a sentence with fear-type, experiencersubject syntax (3a) or frighten-type, experiencer-object syntax (3b):

(3) douyo: uneasiness.

a. Ken douyos the unexpected exam. 
b. The unexpected exam douyos Ken.

The experiencer of the state was unambiguous because experiencers must be animate and only one argument of the verb was animate (e.g., Ken). Stimuli were designed such that eight of the items described habitual attitudes (e.g., the feeling of rivalry), whereas eight described emotional episodes (uneasiness). In order to reinforce this distinction, the former were paired with enduring, long-lived stimuli (e.g., Harvard's basketball team), whereas the latter were paired with ephemeral stimuli (the unexpected exam). The classification was determined in advance by the experimenters. In Exp. 7, they are confirmed by independent raters.

As discussed in ftn. 4, the distinction between verbs that describe habits and events gets obscured in the present tense [cf. Bartholomew failed the exam (yesterday) vs. Bartholomew fails exams (always)]. Thus, to better assess the strength of the mapping between caused events and frighten-type verbs on the one hand and between habitual states and fear-type verbs on the other, verbs were presented in both present tense (Experiment 5a) and past tense (Experiment 5b). The order of verbs was pseudorandomized such that the same condition (emotional episode/habitual attitude) did not occur more than twice in a row. Four test forms were created for each experiment by counterbalancing the order of stimuli (forwards/backwards) and the order of the sentence pairs, each of which was completed by five participants.

Results and Discussion. As Figure 4 indicates, participants were more likely to choose the experiencer-object form for instances than for attitudes, in both Exp. 5a (M=68\%, SE=9\% vs. M=38\%, $\mathrm{SE}=7, d=1.4)$ and Exp. $5 \mathrm{~b}(\mathrm{M}=67 \%, \mathrm{SE}=9 \%$ vs. $\mathrm{M}=41 \%, \mathrm{SE}=9 \% \%, d=1.0) .{ }^{8}$ Logit-transformed results were submitted to by-subjects and by-items ANOVAs. The main effect of the semantic manipulation was significant $\left(F_{1}(1,38)=60.8, p<.001 ; F_{1}(1,38)=49.3, p<.001 ; F_{2}(1,14)=6.1, p=.03\right)$, but the main effect of tense was not $\left(F_{\mathbf{S}}<1\right)$ nor was the interaction of tense and semantics $\left(F_{s}<1\right)$. Thus, English-speakers

\footnotetext{
${ }^{8}$ Means and standard errors and Cohen's d are here and elsewhere calculated by items.
} 
use the semantics of psych verbs to guide expectations about the linking rules governing psych verbs, an effect which replicated across present and past tense.

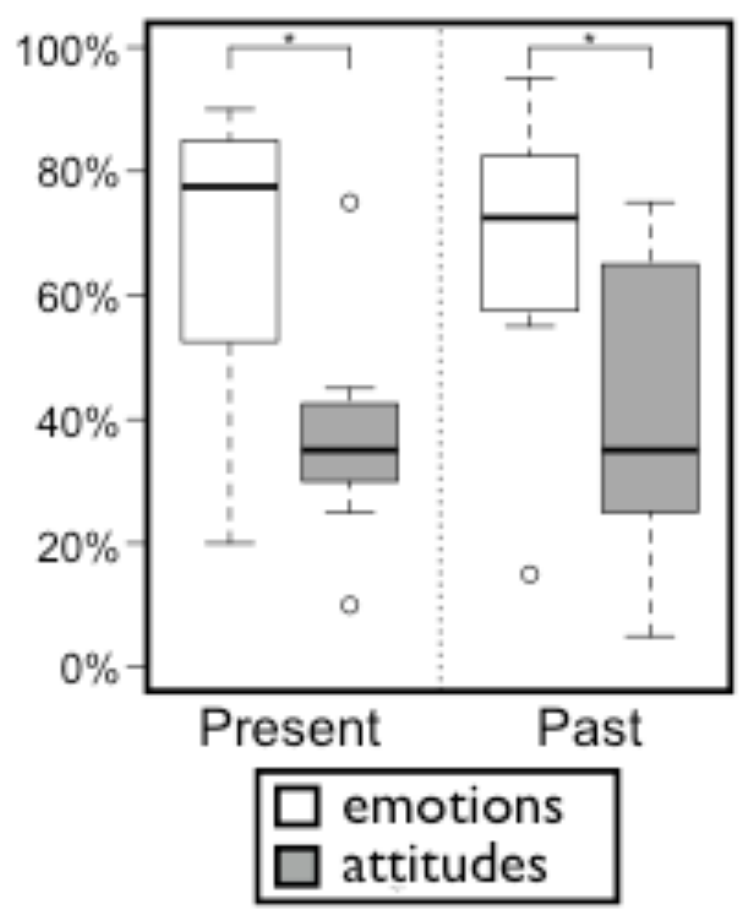

Figure 4. Percentage of participants choosing frighten-type syntax for each verb for novel English verbs in present tense (Exp. 5a) and past tense (Exp. 5b). Note that the boxplots show the distribution over items, not subjects. Error bars represent 1.5 standard deviations.

\section{Experiment 6: Generalization in Japanese}

Exp. 6 closely paralleled Exp. 5. Japanese-speakers were presented with novel "loan words" from English for which there was no Japanese equivalent. For each, they were given a forced-choice judgment between using the verb like a fear-type or frighten-type verb. Crucially, the novel verbs were presented with (Exp. 6c) and without (Exps. 6a-b) the causative-(s)ase- affix.

Method. Sixty Japanese-speaking adults were recruited in public spaces around Tokyo: 20 each in Exp. 6a (20-38 y.o., $\mathrm{M}=22, \mathrm{SD}=13,4$ no answers), Exp. 6b (19-65 y.o., $\mathrm{M}=31, \mathrm{SD}=15)$, and Exp. 6c 
(19-34 y.o., $\mathrm{M}=23, \mathrm{SD}=6)$.

The materials and procedure were analogous to those of Exp. 5. We selected sixteen English nouns describing emotional states for which there is no verb in Japanese. To turn these nouns into verbs, we created loanwords using the semantically neutral, semi-productive verbalizer -r- (e.g., gugu-r-u: 'to google') and made any phonological accommodations necessary to make them pronounceable Japanese words. Again, eight verbs described habitual attitudes (greed) and were paired with enduring stimuli (money), while eight described emotional episodes (jolt) and were paired with ephemeral stimuli (the scene of the murder). Again, participants were presented with the novel verb with its definition (4) and asked to chose between using it in fear-type, experiencer-subject syntax (4a) or frighten-type, experiencer-object syntax (4b):

(4) joruto (jolt): a surprise or shock, esp. of an unpleasant kind and often manifested physically

a. Sono keeji-wa sono koroshi-no genba-o joruto-t-ei-ta

That detective-TOPIC that murder-GEN scene-ACC jolt-V-PROG-PAST

The detective jolted the scene of the murder.

b. Sono koroshi-no genba-wa sono keeji-o joruto-t-ei-ta

That murder-GEN scene-TOPIC that detective-ACC jolt-V-PROG-PASS

The scene of the murder jolted the detective.

In addition, there were four filler sentences involving existing English-derived psych verbs formed with the light verb -suru, two of which are experiencer-subject and two of which are experiencer-object. These filler verbs leant some plausibility to the cover story that we were testing intuitions about new loan words from English. ${ }^{9}$

Exp. 6a, analogous to Exp. 5a, tested unaffixed verbs in past progressive tense, and Exp. 6b,

\footnotetext{
${ }^{9}$ Two of the filler verbs were presented with the wrong object case marker in Exp. 6a. This was fixed in the Exps. $6 \mathrm{~b} \& 6 \mathrm{c}$.
} 
analogous to Exp. 5b, tested unaffixed verbs in present progressive tense. ${ }^{10}$ Causative-affixed verbs were tested in present progressive tense only (Exp. 6c).

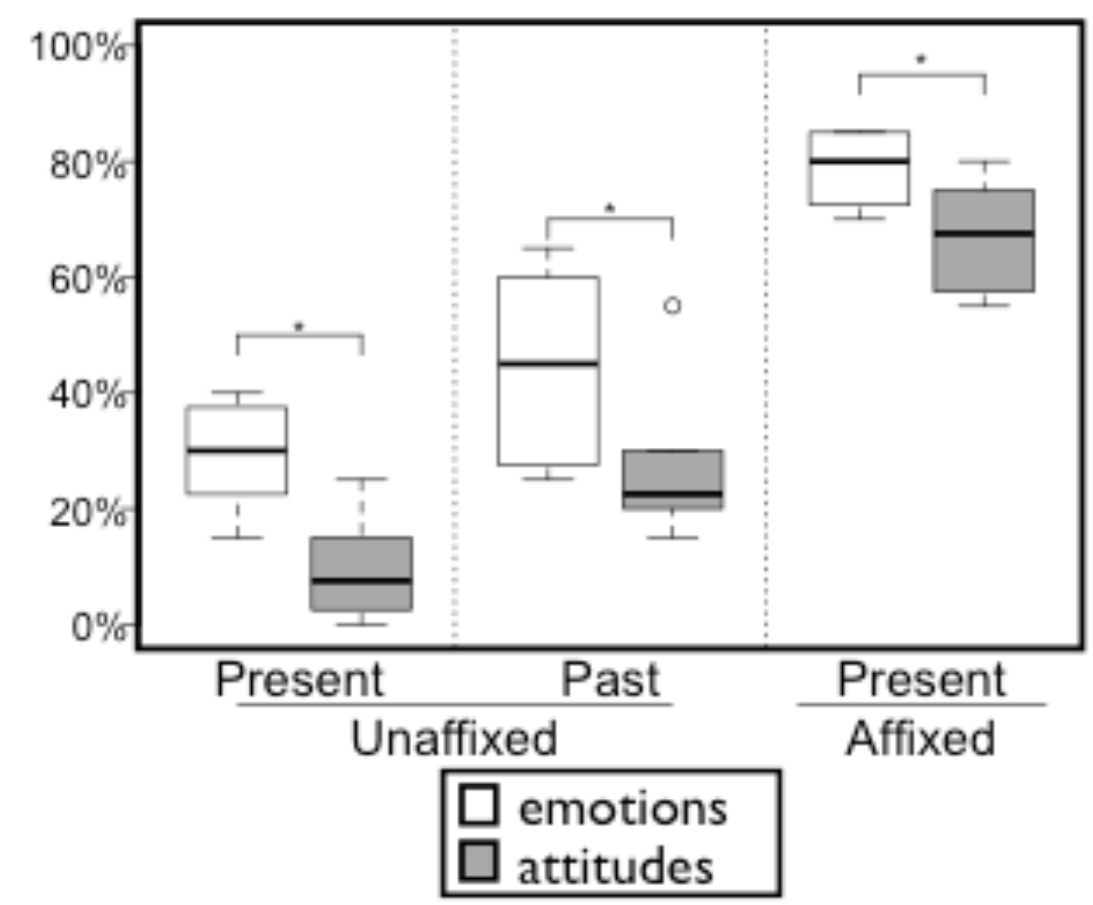

Figure 5. Percentage of participants choosing frighten-type syntax for each verb for novel unaffixed Japanese verbs in present tense (Exp. 6a) and past tense (Exp. 6b) and novel affixed verbs presented in present tense (Exp. 6c). Note that the boxplots show the distribution over items, not subjects. Error bars represent 1.5 standard deviations.

Results and Discussion. Like English speakers, Japanese participants (Figure 5) were more likely to select the frighten-type form for verbs describing emotional episodes than verbs describing habitual attitudes, whether the verb was unaffixed and in present tense (M=29\%, SE=3\% vs. 9\%, $\mathrm{M}=3 \%, d=2.3)$, unaffixed and in past tense $(\mathrm{M}=44 \%, \mathrm{SE}=6 \%$ vs. $\mathrm{M}=27 \%, \mathrm{SE}=4 \%, d=1.2)$, or affixed

\footnotetext{
${ }^{10}$ Unlike English, where fear-type verbs are unnatural in progressive tenses (Agnes was fearing Bartholomew), in Japanese they are most natural in progressive tenses.
} 
and in present tense $(\mathrm{M}=79 \%, \mathrm{SE}=3 \%$ vs. $\mathrm{M}=67 \%, \mathrm{SE}=3 \%) .{ }^{11}$ A 2 (emotional episode vs. habitual attitude) by 3 (Exp. 6a vs. Exp. 6b vs. Exp 6c) ANOVA on logit-transformed results found the expected significant main effects of state duration $\left(F_{1}(1,57)=36.1, p<.001 ; F_{2}(1,14)=19.7, p<.001\right)$ and experiment $\left(F_{1}(2,57)=38.8, p<.001 ; F_{2}(2,28)=110.8, p<.001\right)$. The interaction trended towards significance $\left(F_{1}(2,57)=2.5, p=.09 ; F_{2}(2,28)=2.7, p=.08\right)$. Thus, Japanese-speakers, like English-speakers, are guided by semantics in determining the linking rule that should apply to novel psych verbs, despite the fact that the linking rule is almost entirely predictable from the morphology of the verb. Thus, this provides particularly strong evidence that semantics plays a role in psych verb linking.

Unsurprisingly, Japanese speakers were influenced by morphology as well. They were far more likely to attribute frighten-type syntax to -(s)ase-affixed than unaffixed verbs (see Figure 5), which lead to the significant main effect of experiment mentioned above. This difference was also present in a direct comparison of Exps. $6 \mathrm{c}$ and 6a, which differ only in the use of the affix $(t 1(38)=10.3, p<.001$; $t 2(15)=20.5, p<.001 ; d=4.5)$.

We consider these morphological effects in the General Discussion. Effects of morphology could result from linking rules with different biases or morphological conditions in Japanese and English, but they could also result from a constant set of linking rules (across languages and morphological constructions) but changes in expectations about the semantics of verbs depending on the language or the morphological form of the verb. We return to this issue in the General Discussion.

\section{Experiment 7: The Role of the Stimulus}

In Experiments 5 \& 6, we biased participants to interpret novel verbs as describing habitual attitudes or emotional episodes both with the definition of the psychological state (uneasiness vs. the feeling of rivalry) and the longevity of the inanimate stimulus (the unexpected exam vs. Harvard's

\footnotetext{
${ }^{11}$ To determine what effect tense had, we directly compared Exps. 6a \& 6b, which differed only in the tense of the verb, in an ANOVA, finding main effects of state duration $(\mathrm{F} 1(1,38)=28.6, \mathrm{p}<.001 ; \mathrm{F} 2(1,14)=16.8, \mathrm{p}=.002)$ and tense $(\mathrm{F} 1(1,38)=6.3, \mathrm{p}=.02 ; \mathrm{F} 2(1,14)=21.5$, $\mathrm{p}<.001)$ but no interaction $(\mathrm{Fs}<1)$.
} 
basketball team). Our intention in doing this was to use the enduring or ephemeral nature of the inanimate stimuli to reinforce the differences in the psychological state definitions. However, it is also possible that participants used linking rules that mapped particular kinds of noun-phrases to subject or object position, ignoring the verb's meaning entirely. To investigate this issue, in Exp. 7 (English) and Exp. 8 (Russian) we manipulate only the definition of the novel verb without manipulating the experiencer or stimulus.

Method. Forty English-speaking US residents were recruited through Amazon Mechanical Turk. An additional 12 were excluded for failing to follow directions or for reporting dyslexia.

The 16 definitions of psychological states from Experiment 5 were used. Following our operationalization in Exp. 1 of habitual attitude vs. emotional episode in terms of likely duration, we asked a separate group of 16 English-speaking participants recruited through Amazon Mechanical Turk to rate each state (in lists counterbalanced by order) according to how long it would likely last: seconds, minutes, hours, days, weeks, months or years. ${ }^{12}$ Based on these ratings, the stimuli were divided into eight short-lived states (i.e., emotional episodes) and eight long-lived states (i.e., habitual attitudes). With the exception of two of the items, the classifications were the same as they were in Exp. 5.

Participants were introduced to a novel character, Susan, who has many emotional relationships with friends. For each friend, participants were told Susan that experienced one of the 16 psychological states. Participants were asked to produce a three-word sentence using the novel verb that described this state and used both character's names (e.g., Susan jorutoed Beatrice or Beatrice jorutoed Susan). Because Susan is the experiencer, it is unambiguous whether they applied fear-type or frighten-type syntax to the novel verb. All verbs were presented in the past tense. The two counter-balanced orders from Experiment 5 were used; fillers were not included.

Results and Discussion. Once again participants were more likely to link the experiencer

\footnotetext{
121 additional participant was excluded for reporting dyslexia, and 6 additional participants were excluded for incorrect answers on filler trials.
} 
(Susan) with object position for emotional episodes relative to habitual attitudes (Figure 6; M=52\%, $\mathrm{SE}=6 \%$ vs. $\mathrm{M}=24 \%, \mathrm{SE}=6 \% ; t 1(39)=7.20, p<.001 ; t 2(14)=3.25, p=.01 ; d=1.6)$. These results confirm that the semantics of the novel verb plays a crucial role in the choice of linking rule.

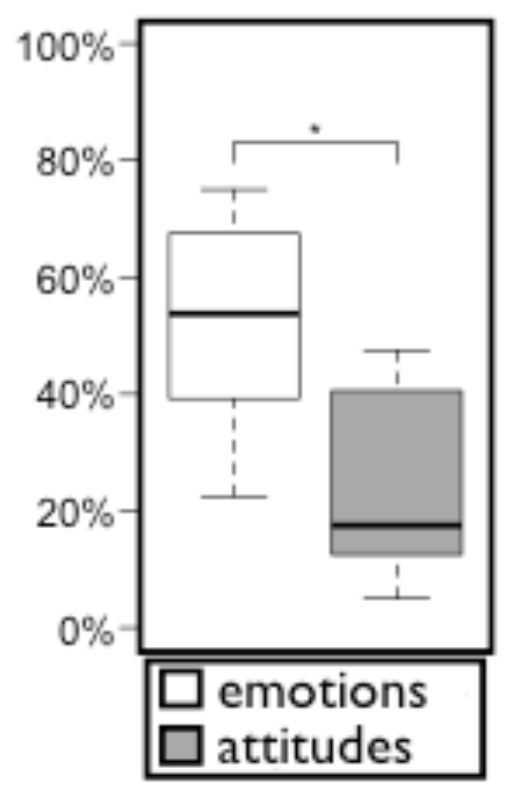

Figure 6. Percentage of participants choosing the frighten-type form for each verb in Exp. 7 (English). Note that the boxplots show the distribution over items. Error bars represent 1.5 standard deviations.

\section{Experiment 8: Generalization in Russian}

Like English and Japanese, Russian has both fear-type and frighten-type psych verbs. Exp. 8 investigated whether the same semantic distinction that drives generalization in English and Japanese also affects Russian-speakers.

Before describing the study, there is one component of Russian grammar that must be briefly reviewed, not because it is likely to have a large effect on our results but because it affects the design of the study. Most Russian verbs are lexically marked for aspect (completedness) and thus are either perfective or imperfective. The aspectual system is complex, but as a rough approximation, perfective verbs describe completed actions, and imperfective verbs describe incomplete actions (for further discussion, see Wade, 2011). 
Whether a verb is perfective or imperfective is often - though not always - predictable based on its morphology and phonology, and thus in designing our study, we had to decide whether our novel verbs would look perfective or imperfective. To ensure that our findings do not depend on this choice, we test novel imperfective verbs in Exp. 8a and novel perfective verbs in Exps. 8b \& 8c. Perfective verbs are frequently derived from imperfective verbs by the addition of one of several prefixes, sometimes accompanied by a phonological change to the stem. To further ensure generality, we test one prefix (po-) in Exp. $8 \mathrm{~b}$ and another (so-) in Exp. $8 \mathrm{c} .^{13}$

There is little reason to expect a sizeable interaction between lexical aspect and psych verb linking. For existing Russian psych verbs there is no clear contingency: $83 \%$ of perfective verbs and $78 \%$ of imperfective verbs are frighten-type verbs. ${ }^{14}$ Indeed, emotional episodes can be either ongoing (imperfective) or completed (perfective), as can habitual attitudes.

Method. Subjects were 259 native Russian speakers (15-71 y.o., M=31, SD=9) participating in the experiment for the first time who did not know Japanese: 94 in Exp. 8a (imperfective), 73 in Exp. 8b (po-perfective), and 92 in Exp. 8c (so-perfective). They were recruited and tested through an Internet experiment portal (gameswithwords.org). Additional participants who did not complete the experiment were excluded, as was one participant who claimed to be three years old.

Stimuli were the 7 longest-lived and 7 shortest-lived emotional states (as rated by a separate group of 10 Russian speakers) drawn from a list of 20 such states, which were based on Japanese verbs for which there was no Russian equivalent. Following the logic in Exps. 1 and 7, we expect the former to be interpreted as habitual attitudes and the latter as emotional episodes.

Sixteen novel verbs were created by adding the -ovat' suffix to Japanese-sounding word stems. This suffix is frequently used for foreign loan verbs and typically results in an imperfective verb. These

\footnotetext{
${ }^{13}$ Note that the choice of prefix can sometimes affect the meaning of the resulting perfective verb. For instance, po- sometimes caries the meaning "to do for a while and stop." Thus, cpat' means "to sleep" and nospat' means "to sleep for a while."

${ }^{14}$ According to our own survey of Russian affect verbs, there are 15 perfective and 23 imperfective fear-type verbs, and 75 perfective and 76 imperfective frighten-type verbs.
} 
were the stimuli for Exp. 8a. Perfective verbs were created by adding the po-prefix (Exp. 8b) or the $s o$ prefix (Exp. 8c). Participants were randomly assigned to experiment. Verbs were randomly assigned to definitions for each participant. In addition, there were six filler items. The procedure for Exp. 8 was identical to that of Exp. 7, except that instead of using the novel verb in a sentence, participants made a forced choice between two possible descriptions of the situation with the novel verb, as in Exps. $5 \& 6$.

Results and Discussion. As expected, Russian-speaking participants were more likely to prefer frighten-type syntax (with the experiencer as the direct object) for verbs describing emotional episodes than they were for those describing habitual attitudes (Figure 7), whether the verb was imperfective $(\mathrm{M}=60.0 \%, \mathrm{SE}=10.2 \%$ vs. $\mathrm{M}=42.2 \%, \mathrm{SE}=10.0 \% ; d=0.7), p o$-affixed perfective $(\mathrm{M}=58.7 \%, \mathrm{SE}=9.8 \%$ vs. $\mathrm{M}=35.8 \%, \mathrm{SE}=9.4 \% ; d=0.9)$, or $s o$-affixed perfective $(\mathrm{M}=63.5 \%, \mathrm{SE}=10.5 \%$ vs. $\mathrm{M}=45.3 \%$, $\mathrm{SE}=8.8 \%, d=0.7$ ). Response proportions were logit-transformed and submitted to 2 (semantics) $\mathrm{X} 3$ (experiment) ANOVAs. The critical main effect of semantics was significant by subjects though not by items $\left(F_{1}(1,256)=118.1, p<.001 ; F_{2}(1,12)=2.5, p=.14\right)$. There was a significant main effect of verb type $\left(F_{1}(2,24)=9.4, p<.001 ; F_{2}(2,256)=3.8, p=.02\right)$, reflecting slightly more choices of frighten-type verbs for so-affixed perfectives. This effect was unexpected and is unlikely to be due to any association between the $s o$ - prefix and frighten-type verbs (to our knowledge, there are no so-prefixed psych verbs). One potential explanation is that the semantics associated with so- is more compatible with the semantics of frighten-type verbs, a possibility that we leave for future investigation. The interaction between morphology and the semantic manipulation was not significant $\left(F_{1}(2,24)=1.2, p=.32 ; F_{2}(2,256)=1.6\right.$, $p=.20$ ). 


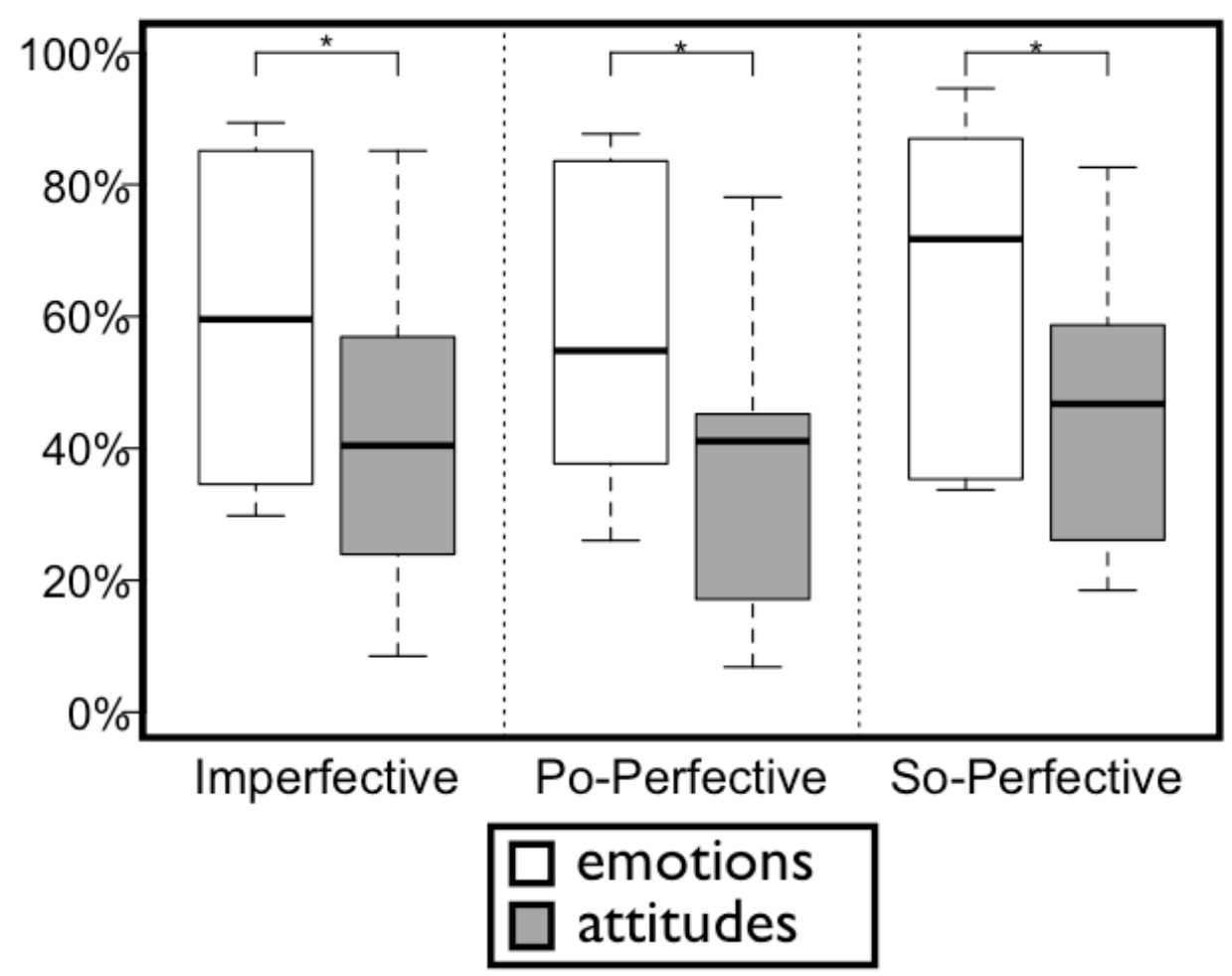

Figure 7. Percentage of participants choosing frighten-type syntax for each verb for novel imperfective verbs (Exp. 8a), po- affixed perfective verbs (Exp. 8b), and so- affixed perfective verbs (Exp. 8c) in Russian. Note that the boxplots show the distribution over items, not subjects. Error bars represent 1.5 standard deviations.

\section{Summary of Generalization Experiments}

In English, Japanese, and Russian, participants were more likely to use frighten-type syntax for novel verbs that described brief emotional episodes than for verbs describing habitual attitudes, and vice versa for fear-type syntax. This indicates that the semantic patterns that we observed in Experiments 1-4 are not simply historical fossils. These linking patterns are part of the linguistic knowledge of adult speakers in all three languages and are actively recruited when learning new verbs. This is particularly remarkable in the case of Japanese where there is a morphological cue that predicts linking patterns with near certainty and thus might be expected to block the learning of any semantic correlation. One obvious 
explanation for these findings is that language development is guided by a propensity to seek out systematic mappings between syntax and semantic structure. If so, we might expect to see the same effects of semantics on verb-learning in young children as well.

\section{Experiment 9: Early Generalization}

Above, we showed that fear-type and frighten-type verbs are systematically distinguishable semantically and that this distinction guides adults' intuitions about language. Both results generalized to several languages and support the systematic mapping hypothesis. However, for these phenomena to have a significant impact on language acquisition through syntactic and semantic bootstrapping, it must be the case that children who are just beginning to acquire psych verbs apply this generalization to guide learning of new psych verbs.

Previous work has shown that children begin psych verb acquisition relatively late. Although toddlers frequently use verbs like like and love, they do so primarily in restricted contexts (e.g., I love you, or I hate that) (see Hartshorne, Pogue, \& Snedeker, in press). It is not until five years of age that they can reliably tell who did what to whom in novel sentences involving fear-type verbs (e.g., distinguishing Lion loved Monkey from Monkey loved Lion) (Hartshorne et al., in press). Successful role interpretation for frighten-type verbs begins a little earlier, but by five years of age children appear to have mastered only a handful of the frighten verbs. ${ }^{15}$ Thus, we tested two groups of children: 4-5 yearolds (who are just beginning to acquire psych verbs) as well as 6-7 year-olds

Method. Participants were 31 4-5 year-olds $(4 ; 0-5 ; 10, \mathrm{M}=5 ; 5)$ and 31 6-7 year-olds (5;117;10, M=7;2). In each age group, 16 children were randomly assigned to the emotional episode condition and 15 to the habitual attitude condition. Children were either brought into the lab or recruited from daycares in the Boston, Massachusetts area. Four children were excluded due to experimenter error.

\footnotetext{
${ }^{15}$ Hartshorne et al. (in press) tested four year-olds on six of the most common frighten-type verbs. In a forced-choice task, children were significantly above chance on surprise, frighten, and scare, at chance (around 50\%) on two of the verbs (amaze, bore), and borderline at one (confuse). It seems reasonable to assume that children would be at chance at lower-frequency verbs, though this has not been tested.
} 
Children were introduced to two novel psych verbs (gorfin and wixter) that either described habitual attitudes or emotional episodes. We used several mechanisms to ensure that children interpreted each verb as belonging to the intended semantic class. First, we based the definitions on actual lowfrequency psych verbs (envy, pity, encourage, and disgust) - verbs which are close to nonexistent in child-directed speech but which describe emotions with which children are likely to have considerable experience. ${ }^{16}$ Second, our descriptions of the verbs either emphasized habitual attitudes (5) or specific instances of emotion caused by ephemeral stimuli (6).

(5) Some people wixter each other. Do you know what wixter is? Wixter is when you want something that somebody else has. Or maybe you think somebody else is so cool you wish you were just like them. That means you feel wixter. Do you feel wixter for anybody? [Discussion] What is your favorite thing to do? [Discussion] What if you knew a kid who got to do [favorite thing] all the time? You'd probably feel wixter, wouldn't you?

(6) Some people gorfin each other. Do you know what gorfin is? You feel gorfin when you see something really, really gross. Or if you had to hold something really slimy, you might feel gorfin. Can you think of any times you felt gorfin? [Discussion] What's the grossest thing you can think of? [Discussion] If you saw that, you might feel gorfin.

Note that in order to induce children to interpret gorfin and wixter as actual words, the words were used

\footnotetext{
${ }^{16}$ This corpus analysis was based on 5,112,439 words of child-directed speech compiled across multiple CHILDES corpora (Bates, Bretherton \& Snyder, 1988; Bellinger \& Gleason, 1982; Bernstein, 1984; Bliss, 1988; Bloom, 1973; Bloom, Hood \& Lightbown, 1974; Bloom, Lightbown \& Hood, 1975; Bohannon \& Marquis, 1977; Brent \& Siskin, 2001; Brown, 1973; Demetras, 1989a, 1989b; Demetras, Post \& Snow, 1986; Demuth, Culbertson \& Alter, 2006; Dickinson \& Tabors, 2001; Haggerty, 1929; Hall, Nagy \& Linn, 1984; Hall, Nagy \& Nottenburg, 1981; Higginson, 1985; Kuczaj, 1977; MacWhinney, 2000; Menn \& Feldman, 2001; Morisset, Barbard, Greenberg, Booth \& Spieker, 1990; Ninio, Snow, Pan \& Rollins, 1994; Post, 1992, 1994; Sachs, 1983; Stine \& Bohannon, 1983; Soderstrom et al., 2008; Suppes, 1974; Valian, 1991; Van Houten, 1986; Warren-Leubecker, 1982; Warren-Leubecker \& Bohannon, 1984; Weist, Pawlak \& Hoffman, 2009; Weist \& Zevenbergen, 2008). It is reported more fully in Hartshorne, Pogue, \& Snedeker (in press). We found 11 instances of encourage, 1 instance of disgust, and no instances pity or envy. We ensured that the children did not, nonetheless, know the verbs by asking them to provide a synonym after each trial. Only in two instances did any child succeed in giving the model verb as a synonym (both children were six year-olds).
} 
multiple times in sentence context, but without indicating what linking rule applies. Specifically, we used the verbs in transitive contexts that were ambiguous as to who the experiencer is (some people gorfin each other) or as nouns (many English psych verbs can be used as nouns or verbs: hate, anger, etc.).

After learning the meaning of the novel verb, the child was read two stories involving the relevant emotion (Figure 8). One character (e.g., Bear) featured as the experiencer in one story but the stimulus in the other. The child was then asked "Who did Bear wixter?" If she applied the fear-type linking pattern, she should give one response (e.g., "Elephant”). If she applied the frighten-type linking pattern, she should give a different response (e.g., "Monkey"). If she was unsure what linking pattern should apply, she should choose at random.

The order of the two verbs was counter-balanced across children. Prior to the critical trials, children did three warm-up trials involving common action verbs (pull, throw, and jump). 


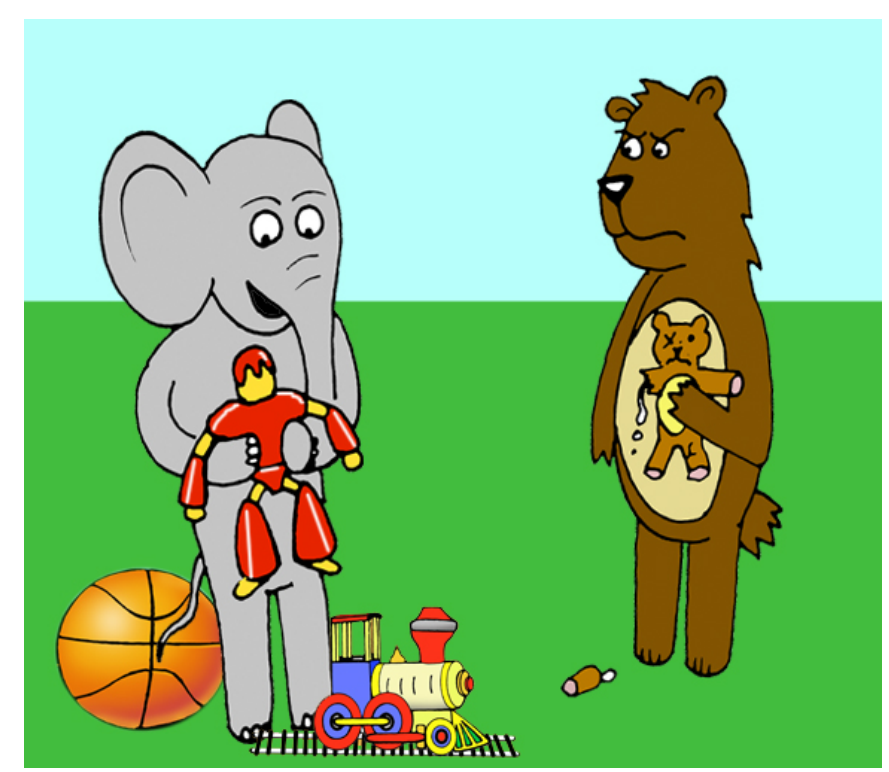

See Elephant and Bear? Elephant has lots of new toys, but Bear's toys were all old and broken. Elephant got new toys all the time, but Bear never got any new toys. Bear always thought Elephant was so lucky.

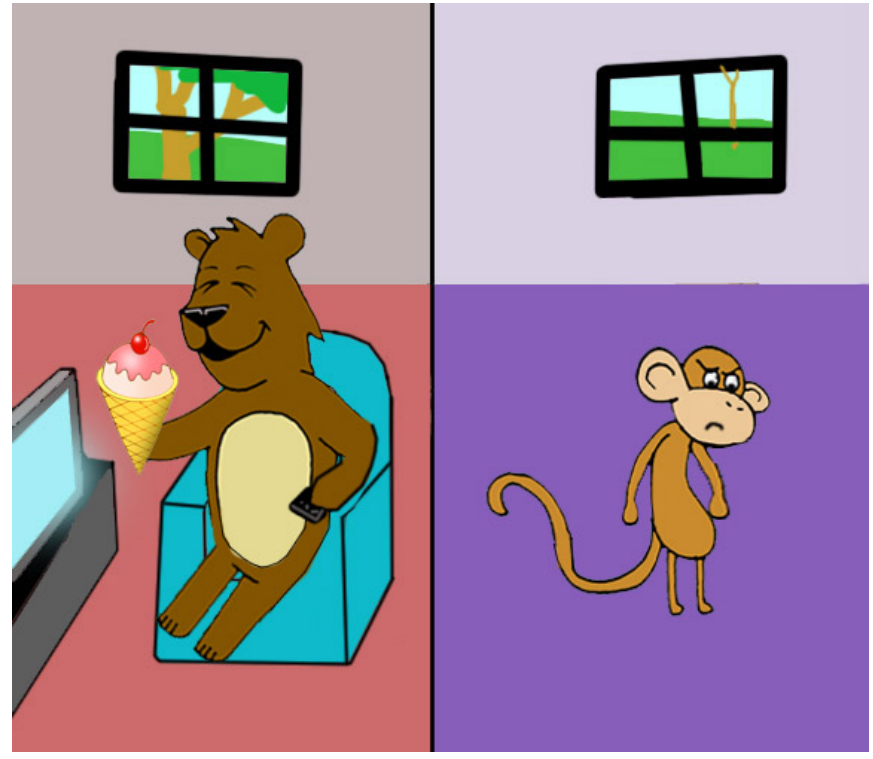

See Bear and Monkey? Bear got to watch TV whenever he wanted, but Monkey never got to watch TV. Bear got to eat as much ice cream as he wanted, but Monkey never got any ice cream. Monkey always thought Bear was so lucky.

Figure 8. An example of a critical trial involving a habitual attitude.

Results and Discussion. As shown in Figure 9, children in both age groups were more likely to interpret the novel verb as frighten-type if its definition emphasized emotional episodes rather than habitual attitudes (4-5 year-olds: $65.6 \%, \mathrm{SE}=8.8 \%$ vs. $33.3 \%, \mathrm{SE}=9.3 \%, d=0.6 ; 6-7$ year-olds: $68.8 \%$, $\mathrm{SE}=7.7 \%$ vs. $26.7 \%, \mathrm{SE}=9.6 \%, d=0.8) .{ }^{17}$ Because there were only two trials, we analyzed the data with a logit mixed effects linear regression with maximal random effects structure, which revealed a main effect of semantics (Wald's $z=2.3, p=.02$ ). There was no effect of age group (Wald's $z<1$ ) nor an interaction of semantics and age group (Wald's $z<1$ ).

Thus, like adults, children who are just beginning to acquire psych verbs also use semantics to guide expectations about the syntax of new psych verbs.

\footnotetext{
${ }^{17}$ Because children were tested on only two verbs each, standard errors and Cohen's $\mathrm{d}$ are calculated by subject both in the text and in the figure.
} 


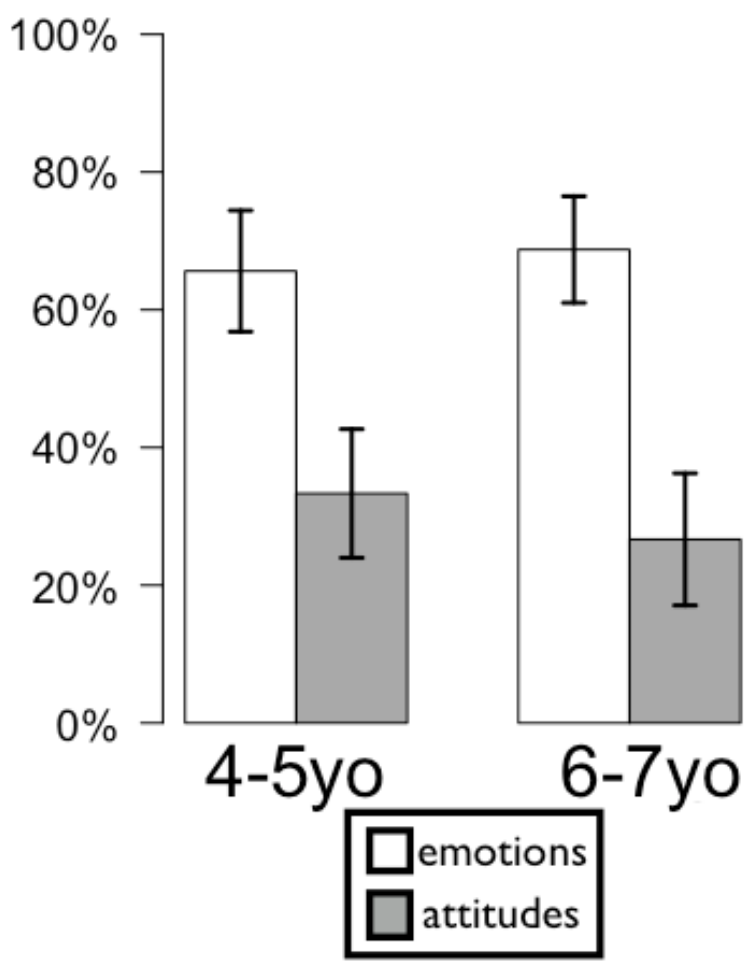

Figure 9. Percentage of participants choosing frighten-type syntax for each verb for novel verbs describing emotional episodes and habitual attitudes in Exp. 9. Error bars show standard errors of the mean.

\section{General Discussion}

In the preceding experiments, we demonstrated that fear-type and frighten-type verbs have systematically distinct semantics (Exps. 1-4). We then showed that this distinction is used productively to guide linking (Exps. 5-8). Finally, we discovered that this ability emerges by four to five years of age, early enough in development to play a substantive role in the acquisition of psych verbs (Exp. 9). These results are inconsistent with accounts in which the linking pattern for each psych verb must be learned individually on the basis of experience (Belletti \& Rizzi, 1988; Culicover \& Jackendoff, 2005; Pinker, 
1984). These results are also inconsistent with some of the previous claims about the semantic basis of psych verb linking rules, such as the suggestion the subjects of both fear-type and frighten-type verbs are causal (Croft, 2012; Talmy, 1995) or the suggestion that for both types of verbs the stimulus is always causal (Dowty, 1991; Rozwadowska, 1992).

Instead, the results support the following systematic, semantically-defined mapping rules: Psych verbs describing habitual attitudes about some entity (fear-type verbs) map their experiencer onto the subject, whereas psych verbs describing a specific episode in which someone is caused to feel some emotion (frighten-type verbs) map their experiencer onto the object. Critically, this analysis generalizes across several languages (English, Mandarin, Korean, Japanese, and Russian). That fact has three implications: it shows that systematic mappings are available to learners of each of these languages; it demonstrates that the same semantic classes and linking patterns are present across unrelated languages, and; it suggests that the existence of these two classes is not an historical accident but instead reflects a more enduring property of language or our construal of affective states.

More broadly, these results provide strong support for the claim that, throughout the lexicon, mappings from semantics to syntax are systematic. While there are many cases of apparent conflicts in the linking rules, psych verbs have long been considered one of the most intractable, thwarting theorists who seek a semantically transparent syntax (e.g., Culicover \& Jackendoff, 2005; Pinker, 1984). Researchers have disagreed about whether there is any semantic distinction between the two classes of verbs and about what it might be (see Introduction). The fact that this particularly tricky case can be resolved semantically provides reason to believe that the other problematic cases can be similarly resolved as well.

As noted in the Introduction, many theories of language acquisition rely on some form of the systematic mappings hypothesis to solve critical learning problems, such as discovering how syntactic categories are marked (semantic bootstrapping, Grimshaw, 1981; Pinker, 1984) or acquiring the 
meanings of verbs (syntactic bootstrapping, Gleitman, 1990). To the extent that the mappings are arbitrary, these learning procedures will fail, and thus studies like ours are critical for the viability of semantic and syntactic bootstrapping. Conversely, our findings call into question the necessity of a conservative learning strategy, where linking rules are progressively generalized from learned examples - a strategy adopted by many constructivist accounts (e.g., Boyd \& Goldberg, 2012; Tomasello, 1992). While such a strategy may be ideal if linking rules are highly unpredictable across languages and subject to numerous exceptions, it is curiously suboptimal if - as we claim here - linking is reasonably predictable and systematic. Note that while in the literature, conservative learning approaches are often associated with construction grammars, conservatism of learning and syntactic formalisms are in principle orthogonal: a construction grammar learner who is armed with strong priors about the nature and scope of linking generalizations (e.g., that linking tends to care about animacy and causality but not color or age) could potentially have strong expectations about psych verb linking prior to having learned many or any psych verbs - much as our children in Exp. 9.

In the remainder of this discussion, we first discuss the role of causal affixes in languages such as Japanese. Next, we re-examine the previous psycholinguistic work on psych verbs in light of our results. We then discuss recent developmental work on psych verbs. Finally, we explore why languages might have these two different types of verbs: Specifically, we discuss the kinds of semantic structures that could encode these two construals of emotion, how these structures would interact with a simple mapping rule to produce both sentence types, and why many languages have both construals.

\section{Causal Morphemes and Linking Rules}

Although speakers of English, Russian, and Japanese were all sensitive to our semantic manipulation in applying linking rules to novel psych verbs, Japanese speakers were much more likely to choose the frighten-type pattern for causally-affixed verbs and the fear-type pattern for unaffixed verbs. In contrast, Russian and English speakers - whose languages provide no morphological cue to 
psych verb linking - showed no strong overall bias towards either frighten-type or fear-type readings.

Note that participants were not merely frequency matching. In both English and Russian, the overwhelming majority of psych verbs are frighten-type verbs, yet participants showed at best a small bias in favor of frighten-type verbs (collapsing across the semantics manipulation). Instead, it appears that Japanese speakers were able to use the existence of a causal affix in their language to make strong predictions about linking. This behavior is consistent with the finding that native speakers of Japanese have difficulty learning frighten-type verbs (but not fear-type verbs) when they are learning languages that do not have these affixes (Montrul, 2001). Historical data also points to a role for morphology: Many modern English fear-type verbs evolved from frighten-type verbs as English was in the process of losing its causative morphology (van Gelderen, in press).

There are at least two ways in which the morphology of the verbs could explain the pattern of results. First, people might learn a direct relationship between morphology and linking patterns: Japanese speakers learn that causally-affixed psych verbs are more likely to take the frighten-type pattern. This expectation would be independent of the expectation that emotional episodes will take the frighten-type pattern and, given the numbers in Exp. 6, this morphosyntactic constraint would also have to be stronger. Alternatively, the effect of morphology could be mediated by semantics: Japanese speakers may learn that causally-affixed psych verbs usually describe caused emotional episodes, whereas unaffixed verbs usually describe habitual attitudes; the linking rules apply as normal. On this account, we would have to assume that the Japanese participants interpreted the verbs differently than we had intended, giving them distinct semantic interpretations depending on the morphology of the verb. This leads to a straightforward prediction that can be tested in future research. This account parallels prior findings on the interpretation of mass/count syntax in languages like English (see Barner, Li \& Snedeker, 2010). Any object can be construed of as individuated kind or as a portion of some substance. The use of mass or count syntax, in a language like English, provides information about which construal 
to take. In the absence of this information (e.g., in classifier languages like Chinese) construal depends largely on the referent.

\section{Implications for Previous Psycholinguistic Work}

As we noted in the Introduction, there are two lines of research which suggest that frighten verbs are more difficult for adults than fear verbs. First, adults learning English are slower to acquire frighten verbs than fear verbs, making more errors in comprehension, production and judgment tasks (Chen, 1996; Sato, 2003; White et al., 1998). Second, individuals with agrammatic aphasia have difficulty producing and comprehending simple active sentences with frighten-verbs, but perform well above chance with fear-verbs (Pinango, 2000; Thompson \& Lee, 2009). In both of these cases, the errors often involve treating the frighten-verbs as if they were fear-verbs (e.g., interpreting the subject as the experiencer). One tempting interpretation of these findings is that fear-verbs follow a canonical mapping rule that links experiencers to subject position, one which is available to adult learners and requires few syntactic resources. In contrast, frighten verbs are exceptions to this standard linking pattern and thus require additional knowledge or syntactic resources to process (White et al., 1998; Sato, 2003). Our results, however, are in clear conflict with this interpretation--we found that both young children and adults extended the frighten-type mapping when the meaning of the verb justified it, demonstrating that this linking pattern is quite productive. Thus we must look for another explanation for the earlier findings. There are two promising possibilities

First, aphasics and late learners could be relying on animacy-based heuristics that facilitate the interpretation of fear-verbs and hinder the interpretation of frighten-verbs. There is a strong tendency within English and across languages - for subjects to be animate and for direct objects to be inanimate. This pattern shapes both comprehension and production. For example, studies employing the N400 as an index of online interpretation have found that readers expect animate subjects and integrate them more easily than inanimate ones (Weckerly \& Kutas, 1999) and that we initially process inanimate direct 
objects more deeply than animate ones (Paczynski \& Kuperberg, 2011). We tend to misremember sentences that violate this ordering and we judge them to be less acceptable (MacDonald, Bock \& Kelly, 1993).

The experiencer of psychological state is necessarily animate. The cause or target can be an animate, but it is more often an event, abstraction or object (see Levin \& Grafmiller, 2013). Thus, in simple active sentences, fear verbs will typically respect the broader pattern of the language (with animate subjects, and many inanimate objects), while frighten verbs will often violate it (with animate objects, and many inanimate subjects). Most psych verb researchers avoid animacy confounds in their materials by using sentences with two animates (The man feared/frightened the woman). Nevertheless, the contingency is present in the language at large and thus aphasics and late learners may have developed a strategy of expecting the necessarily animate argument to appear in subject position. Critically, this animacy hypothesis makes predictions that distinguish it from the claim that frighten verbs are exceptional and thus difficult. In passive sentences, the animacy bias will favor frighten-verbs (because the surface subject will be the experiencer which is necessarily animate) but it will hinder fearverbs. In contrast, if frighten-verbs are deviant, then they should continue to be problematic in their passive form. Agrammatic aphasics have been tested on this contrast and perform precisely as the animacy hypothesis would predict: they produce and understand passive sentences with frighten-verbs more accurately than passive sentences with fear-verbs (Pinango, 2000; Thompson \& Lee, 2009). To the best of our knowledge there are no studies that compare the performance of second language learners on fear and frighten verbs in the passive voice, but the predictions are clear. ${ }^{18}$

\footnotetext{
${ }^{18}$ The alert reader may wonder whether this animacy bias should be construed of as another linking rule since it plays a role in mapping meaning to syntactic form. Most theories of argument linking make a distinction between an argument's position in the surface structure of a sentence and an argument's grammatical relation, though the names of these levels and how they are conceptualized varies considerably (see Levin \& Rappaport-Hovav, 2005, pp.26-7 and pp. 196-7). This distinction is critical to understanding the passive: The object of an active sentence and the subject of the passive have the same grammatical relation but different realizations in the surface syntax. The animacy bias described above is relationship between conceptual features and the surface form (favoring all animate subjects) rather than a relationship between conceptual features and grammatical relations (which would favor animate active subjects but not animate passive subjects). In this way, this animacy bias is different than the linking rules that are the focus on this paper, which determine mappings
} 
The second possibility is that frighten-verbs are harder because they appear in more variable syntactic frames making it more difficult for adults to learn their argument structure and creating competition between these frames during language processing. In experimental studies, aphasics and typical adults often choose to use passives for frighten-verbs (16\% -70\% of the time) but rarely use passives for fear-verbs (Ferreira, 1994; Thompson \& Lee, 2009), perhaps because - as we noted above in their active form frighten-verbs often violate the preference for animate arguments to appear in subject position. This suggests that for a frighten-verb the active and passive forms will often be similar in frequency, resulting in competition between them, while for fear-verbs the active form will dominate.

These two explanations are mutually compatible and appear to provide better explanations of the existing data than the hypothesis that frighten verbs involve exceptional linking, Either of them would be consistent with the present data and our claim that frighten-verbs and fear-verbs have distinct semantic structures, which are subject to a single set of mapping rules that can explain both patterns of argument realization. ${ }^{19}$

\section{Implications for Previous Developmental Work}

Prior work on children's acquisition of psych verbs has also primarily focused on the question of whether one of the two types of verbs is more difficult. The initial studies focused on errors in children's spontaneous production and reported inconsistent findings. Lord (1979) found errors in which frightenverbs were produced with fear-syntax in children from 3 to 8 , but she did not report any errors with fearverbs. In contrast, Bowerman (1990) reported more errors in which fear-verbs were produced with frighten syntax, but found errors of both kinds. However, the total number of errors was quite small and

between meanings and grammatical relations. This appears to be broadly true of effects of animacy on argument realization across languages (see Levin \& Rappport-Hovav 2005, p.127 and p. 182).

${ }^{19}$ Some of the difficulties that second language learners have in learning frighten-verbs could stem from cross-linguistic differences in how these verbs are formed. In languages like English, frighten-verbs are not derived from fear-verbs and instead are generally monomorphemic. In contrast, languages like Japanese and Turkish have a productive overt causative morpheme that builds frighten-verbs from fear-verbs. Adults whose first language employs the one strategy will have difficulty acquiring the other. But negative transfer alone cannot account for the entire data pattern: speakers of French and Spanish who are learning English have more difficulty with frightenverbs than fear-verbs even though their native languages are similar to English in terms of causal morphology (Chen, 1996; White et al., 1998; see also Montrul, 2001). 
the data were, by necessity, filtered by the attention and memory of the observer. Critically, Bowerman found none of these linking errors in children under 6 and concluded that until this age children learn the psych-verb linking patterns in a piecemeal fashion. Our data demonstrate that this claim is wrong, or at least too strong. By 4 to 5, children systematically extend the two linking patterns based on the nature of psychological event.

More recently, we explored children's comprehension of existing psych verbs (Hartshorne, Pogue \& Snedeker, in press). We found that English-speaking children develop a robust understanding of fear-type verbs significantly later than frighten-type verbs. Specifically, they often interpret fear-verbs as if they were frighten-verbs, treating the object as the experiencer, despite the higher token-frequency of the fear-verbs in child-directed speech. One of the possibilities that we raised in that paper is that fear-type verbs are a hard-learned exception to a more general linking rule (e.g., linking causes and subjects). This hypothesis, however, is clearly inconsistent with the results of Exp. 9, in which children had no particular difficulty acquiring fear-type verbs.

However, in that paper we considered a second hypothesis which is consistent with the present results. Logically, children can only learn a verb if they can figure out what it means. This requires that they encode the relevant events in the world when they hear the verb used. Perhaps frighten-type verbs are learned more readily because they have clearer perceptual correlates in the immediate context than fear-verbs. A difference in perceptual correlates should be expected if frighten verbs describe specific emotional episodes, while fear verbs describe habitual attitudes. For example, one can say "Bartholomew fears Agnes" even when Bartholomew is asleep and Agnes is out of the country, but when we say "Agnes frightens Bartholomew" she is likely to be in the same room as Bartholomew and doing something noticeably frightening. Thus, it may be much harder for the child learner to guess exactly what a speaker is referring to when he uses a fear-type verb (for relevant discussion, see Gleitman, 1990). This challenge was presumably mitigated in Exp. 9, because we provided clear and 
explicit information about which events each of the verbs described.

\section{Two Conceptualizations of Emotions}

Above, we argue that fear verbs and frighten verbs describe two very different conceptualizations of emotional states, drawing on previous work by Pesetsky (1995) and Pylkkanen (1999) and the distinction in the affective state literature between emotions and dispositions (Ekman, 1992). Specifically, we proposed that frighten verbs are used to encode an episode in which one entity causes another to experience an emotion. In contrast, fear verbs encode an experiencer's habitual attitude about a target (leaving aside the question of what caused this attitude). In each of the languages that we looked at, these two construals were mapped onto syntax in a similar way: for the frighten-verbs the cause of the emotional episode is the subject and the experiencer is the object, while for the fear verbs the entity that has the habitual attitude is the subject. This pattern is consistent with the broader linguistic literature on psych verbs: while there is morphosyntactic variation in how these arguments are expressed (particularly for the fear-verbs), we know of no reports of languages in which the causal psych verbs appear with experiencer subjects, while habitual attitudes have experiencer objects (for summaries of the cross-linguistic patterns see Croft, 1993; Grafmiller, 2013; Landau, 2010; Levin \& Rappaport Hovav, 2005). The cross-linguistic stability of this pattern raises several related questions. Why is the mapping from semantics to syntax so similar across languages? Why do these particular semantic distinctions get encoded rather than other possible distinctions? Why do languages lack simple constructions that express both the cause of the emotion and the target of that emotion?

The answers to these questions will depend in part on the grain size of our linking rules. So far in this paper we have discussed linking rules as if they were narrow generalizations, with a different rule for each semantically-defined verb class (e.g., externally caused change of state verbs, manner of motion verbs, or fear-type verbs). If this were the way in which learners represented linking rules (the only relevant grain size), then they would need to acquire dozens, or even hundreds, of these 
rules (see e.g., the verb classes in Levin, 1993). Any cross-linguistic similarities in these rules would have to be attributed to the biological evolution of language, constraints on non-linguistic cognitive prcoesses, or the communicative pressures that shape languages in historical time. This imposes an enormous challenge for both nativist and empiricist theories: For each rule in the set, we must determine what these cognitive or communicative constraints are and how they gave rise to the linking rule over phylogenetic or historical time. A more attractive possibility is that the linking patterns for different verb classes are simply instantiations of a single broader principle that constrains the mapping from meaning to form. Below we sketch out an account of this kind for the two classes of psych verbs, drawing heavily on Pesetsky (1995), as well as a larger literature on the semantic structures that underlie verb meaning and argument realization (see Levin \& Rappaport-Hovav, 2005). ${ }^{20}$

Semantic Structures and Clean Mappings. Linking rules describe the relationship between two representations: a semantic representation that encodes the relevant aspects of the sentence meaning and a syntactic representation which captures its form. The possible linking rules depend on the nature of these representations. Early linking theories generally conceptualized meaning as a list of thematic roles that could be assigned to arguments (experiencer, agent and theme) or a set of entailments that those arguments might have (is sentient, is moved) (see Levin \& Rappaport-Hovav, 2005 for review). Over time, however, there has been a systematic shift toward theories in which verb meanings are structured semantic representations that include both a verbal root and one or more primitive predicates (see e.g., Jackendoff, 1990; 2002; Pinker, 1989; Rappaport Hovav \& Levin, 1998; 2011). These primitive predicates encode aspects of meaning that are present in many different verbs, and they can be used in combination (by embedding one predicate within another) to form more complex semantic

\footnotetext{
${ }^{20}$ To be precise, the analyses that we provide for these two classes of verbs are modeled directly on Pesetsky (1995). However Pesetsky works in a theoretical framework in which there is no separate level of semantic structure to be mapped onto syntax. Instead, all structure is built in the syntax itself (see Hale \& Keysar, 1993). Thus, for Pesetsky, structures similar to those in Figures 10 and 11 would be early steps in a syntactic derivation. These two ways of viewing the linking problem result in surprisingly similar descriptions of many phenomena (see Levin \& Rappaport Hovav, 2005). We have chosen to reframe Pesetsky's proposal in terms of semantic structures because doing this allows us to use terms like syntax and semantics and have them mean approximately what our audience is likely to think that they mean.
} 
structures. These semantic structures capture the commonalities across verbs within a single semantic class. Figure 10 provides some examples of the semantic structures proposed for a few common verb classes (note that these representations have been simplified slightly for expository purposes). Critically, both Pinker (1988; 2007) and Jackendoff (2002) propose that these semantic structures are available prior to language acquisition and have their origins in the infant's conceptual system.

A critical advantage to this kind of theory is that it opens up the possibility of replacing a large set of mapping rules (based on specific thematic roles or verb classes) with a few broad principles based on the geometry of the semantic tree (Levin \& Rappaport Hovav, 2005). This is illustrated by the examples in Figure 10. In each case, the argument that is highest in the semantic structure is the one that becomes the subject of an active sentence (the highest argument in the syntactic tree), while the argument that is lower in the semantic tree becomes the direct object or a prepositional object. Thus differences in structural prominence are preserved in the linking from semantics to syntax: arguments that are more deeply embedded in the semantic representation are also more deeply embedded in the syntax. Prominence preservation is robust both within and across languages, leading many theorists to propose that learners have a strong preference for clean and simple mappings between meaning and form (Bouchard, 1995; Jackendoff, 1992; Levin \& Rappaport Hovav, 2005; Wechsler, 1995; Williams, 2003).
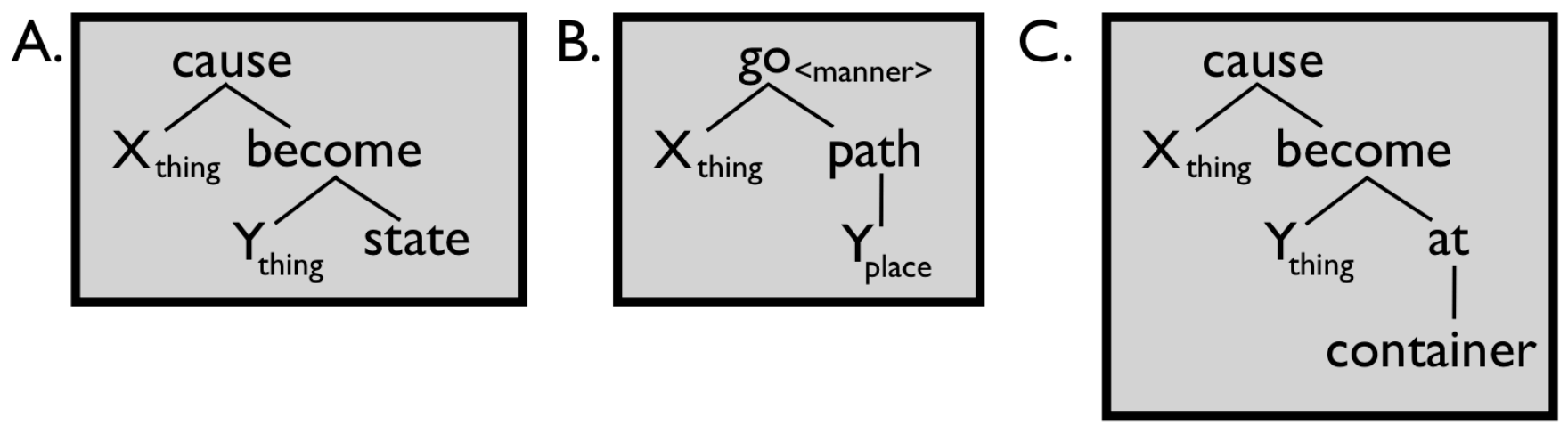

Figure 10. Examples of the semantic structures for some common kinds of verbs. (A) represents events 
such as Agnes breaking a vase or Bartholomew searing the tuna. (B) represents events such as Agnes walking to the store or Bartholomew swimming the English Channel. (C) represents events such as Agnes pocketing the change or Bartholomew shelving a book. These examples are based on Levin and Rappaport (2011) but have been simplified for expository purposes. The variables mark the position of arguments in the semantic structure while the italics mark the material that is encoded in the verbal root.

Figure 11 provides possible representations for habitual attitudes and caused emotional episodes in a theory of this kind. For the habitual attitudes (11a) the highest predicate is BE which takes two arguments, an entity that is in a particular state (the experiencer) and the state that $\mathrm{s} / \mathrm{he}$ is in (in this case an emotional state). The emotional state is itself a complex object consisting of a modifier (the verbal root which specifies the kind of emotion) and the entity that this emotion is directed toward (the target). If prominence relations are preserved during linking, then the experiencer will become the subject of the sentence because it is higher in the tree (less embedded) than the target. In the case of the caused emotional episodes (11b), the highest predicate is CAUSE which takes two arguments, the entity that is causing the event and the predicate BE which describes the state that is being caused. Here again, BE takes two arguments: the entity experiencing the emotion and the emotional state itself. Consequently, in Figure $11 \mathrm{~b}$, the cause is higher in the tree than the experiencer and should appear as the subject of the sentence.

Thus an overarching bias to preserve structural asymmetries during linking could explain the cross-linguistic pattern in which habitual attitudes are expressed as experiencer subject verbs (fear verbs) and caused emotional episodes are expressed as experiencer object verbs (frighten verbs) (cf. Grafmiller, 2013; Levin \& Rappaport Hovav, 2005). 
This theoretical shift, from many mapping rules to one broad bias, radically changes the acquisition story. For any empiricist who is willing to accept early semantic abstraction, it opens up the possibility that children discover prominence preservation in the process of learning their first transitive verbs, and then immediately apply it to verbs for psychological states. For the nativist, this proposal reduces the burden on evolution at no loss to the learner. When the construal of an event is unambiguous (e.g., caused motion), children can use their expectations about prominence and mapping to figure out the syntax (the causer is subject). When the construal of the event is unclear then knowledge of syntactic structure and expectations about prominence can help clarify the meaning that should be attributed to the verb (e.g., if the experiencer is lower than the stimulus, then the event is being construed as a caused emotional episode). Critically, this proposal reduces the distance between the viable nativist and empiricist theories of acquisition. An empiricist learner who is figuring out the linking rules verb-byverb is radically different from a nativist infant equipped with dozens of innate linking rules. But an empiricist infant who is alert to broad generalizations about how meaning maps to form is just a few leaps away from the nativist infant who expects prominence to be preserved. While this proposal is both intriguing and promising, there is much left to be done to fully investigate it, including more extensive typological studies and research into how children acquire other verb classes where semantic embeddedness can (or cannot) disambiguate the linking patterns (assuming any such exist).
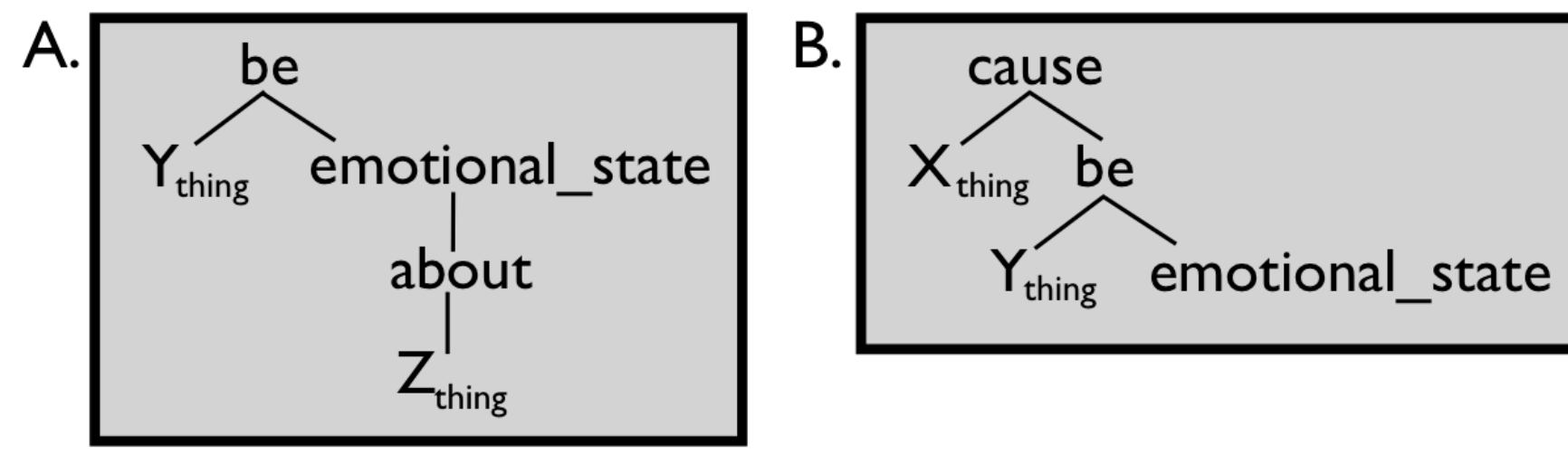
Figure 11. Possible semantic cores for habitual attitudes (A) and caused emotional episodes (B).

Where do these semantic structures come from? The proposal above assumes that adults and children have abstract, highly-structured semantic representations which highlight some features of events (e.g., causal relations and predicate/argument structure), while placing others in the background (e.g., the identity of the arguments or the content of the verbal root). This raises the questions of where these structures come from and why they contain the information that they do. There are three broad possibilities.

First, these semantic structures could be an innate feature of the language faculty. The classic nativist theories of the last century assumed that children solve the mapping problem by employing innate semantic categories, innate syntactic categories, and principles for linking them (e.g., Baker, 1988; Pinker, 1984). On these theories, the content of predicate-argument structures is determined by whatever forces account for the evolution of language. Contemporary theories of predicate-argument structure diverge from these classic accounts in several ways, but the core commitment to innate, domain-specific representations remains intact. For example, most researchers in mainstream generative linguistics now conceptualize predicate-argument structure as a part of the syntactic derivation, and not as a semi-autonomous semantic structure (see e.g., Hale \& Keysar, 1993; 2005; Harley, 2011; Pesetsky, 1995). This theoretical choice is motivated, in part, by the conviction that these predicate decompositions are linguistic structures and that there is just one combinatorial engine for generating linguistic structure. The challenge for these accounts is to identify the evolutionary pressures that gave rise to these structures and the biological mechanisms that allow development to be constrained to this degree.

Second, these semantic structures could be conceptual representations, which are not strictly part of the language faculty, but instead evolved prior to language, allowing us to represent the central 
features of events and reason about them (Jackendoff, 2002; Pinker 2007). On this theory, children acquire basic clausal syntax by trying to map the sentences that they hear onto pre-existing representations of events. Commonalities across languages result from similarities in these event representations and in the procedures that guide this mapping. Notions like cause or change of state play a central role in linking patterns because they are explicit parts (subpredicates) of our non-linguistic event representations. Notions like distance, color and temperature, which are critical in other domains, do not play a role in linking patterns because these features are not explicit in the event representation (they are only encoded implicitly in the root). ${ }^{21}$ Proposals like this, which ground acquisition in the child's prelinguistic conceptual categories, have a long history in cognitive science (Brown, 1973; Bowerman, 1973; Braine, 1976; Clark, 2004; Pinker, 1988; Slobin, 1985). They have two clear advantages over domain-specific nativist proposals: they radically increase the time over which evolution could be at work and they open up the possibility that children's nonlinguistic experiences with events provide critical data for acquiring these representations. The burden of these conceptual proposals is to demonstrate that the relevant representations exist in nonlinguistic primates and prelinguistic children. Doing so will be tricky. It requires more than just showing that infants make inferences that we see as reflecting an understanding of causes and goals. It requires demonstrating that there is a unitary concept of cause or goal that lurks behind the inference, and which has approximately the same scope as the category implicated in our linking rules. It also requires us to show that conceptual features that are irrelevant to linking rules (red vs. blue, up vs. down) are not part of this representation. While we are a long way from reaching this goal, the existing work in infant cognition provides reasons to be optimistic. We know that infants are able to represent causes, path and goals in some fashion and

\footnotetext{
${ }^{21}$ This raises the question of why some conceptual features are encoded in event representations and others are not. Presumably the answer lies in understanding the nonlinguistic function of this level of representation. If it primarily serves to establish links between a predicate and its arguments, then it might be most useful and efficient for this representation to include the information that is needed to distinguish between the different roles in a single event, to exclude information that is already encoded in the verbal root or nouns, and to make use of primitives that are general enough to be reused across many event types. These constraints could shape event representations over either evolutionary or developmental time.
} 
that they distinguish between entities that can act as agents and those that cannot. In fact many of the conceptual features that are central to linking rules also play a prominent role in theories of how infants represent events and reason about them (for reviews see, Baillargeon \& Carey, 2012; Carey, 2009; Lakusta, Wagner, O’Hearn, \& Landau, 2007; Spelke \& Kinzler, 2007).

A third possibility is that the semantic features that guide linking rules are selected from a much larger set of conceptual primitives by the communicative pressures that shape languages over historical time. On this account, constructs like cause, possession, and change of state are encoded in linking rules because they result in more stable and efficient communicative systems, while constructs like color and temperature do not. Each generation of children breaks into language acquisition by mapping utterances to the larger set of conceptual features and then discovers the features that matter by tracking the patterns in the input. This account has two clear burdens. The first is to describe the relevant communicative pressures and how they account for the apparent cross-linguistic stability in the content of linking rules (see Levin \& Rappaport-Hovav, 2005). The second is to determine how children could close in on the correct set of conceptual distinctions and then to test this account with studies of language acquisition. While theories invoking historical evolution and communicative pressures have attracted interest in recent years (Chater \& Christiansen, 2010; Gibson, Piantadosi, Brink, Bergen, Lim \& Saxe, 2013; Piantadosi, Tily \& Gibson, 2011), we know of no systematic work on how these processes could account for the semantic structures that underline linking rules. One way to probe the role of historical evolution is to explore the properties of homesign (gestural systems created by isolated deaf individuals). These systems are reported to have word order regularities (Goldin-Meadow \& Mylander, 1990; Coppola \& Newport, 2005) which are described using the semantic labels that are used to characterize linking rules in spoken language (e.g., agents, experiencers and recipients). We know of no work that systematically probes the semantic basis of word order in home sign, but if these systems do draw on the same subset of features as natural languages, then it would suggest that semantic 
structures are properties of the human mind that are available within a single generation and do not emerge over historical time (or, alternatively, communicative pressures are sufficiently powerful to give rise to the appropriate semantic features within a few years).

Why do languages encode these two construals of emotion? Above we discussed the origins of semantic structures in general terms, rather than focusing specifically on psych verbs. This is because the semantic structures that we are considering for psych verbs are made up of many of the same components as the structures for other kinds of events (compare Figure 11 with Figure 10). But our analysis also raises a narrower question about apparent gaps in the psych verb repertoire. Fear verbs, we argued, encode habitual attitudes toward a target, while frighten verbs encode the cause of an emotional episode. But there are other conceptualizations of psychological events that we could build using this same set of semantic tinker toys. Specifically, one might want to describe the causes of a habitual attitude, but while language allows us to do this with periphrastic constructions (Because of her idyllic upbringing, Alice trusted everyone.), we know of no language in which there are verbs or simple constructions devoted to expressing this construal. Similarly, we are unable to easily encode the target of the caused emotional episode (7) (see Pesetsky, 1995).

(7) * The newspaper frightened John about the housing bubble These systematic gaps in the expressive power of language are presumably attributable to one or more of the forces described above (language specific evolution, cognitive constraints or historical change). For example, Pesetsky (1995) pursues the hypothesis that innate domain-specific features of language can account for why frighten verbs do not encode the target of the emotion (see 7). Alternately, these gaps could reflect historical pressures on lexicalization. While we can invent situations where the cause and the target are distinct (as in 7), it is often possible to infer the target from the cause. Typically, when John frightens me, I'm afraid of John or something that he might do. Perhaps the need for distinguishing these two roles is so rare, that languages cannot sustain this argument structure. 
One intriguing possibility is that these gaps are attributable to the properties of the predicates that semantic (or conceptual) structure and thus can be used to refine our semantic analyses. Notice that the structures we provided in Figure 11 actually predict that sentences like (7) should be possible: The BE in $11 \mathrm{~b}$ is the same as the BE in $11 \mathrm{a}$ and both take an experiencer and an emotional state as their arguments, and so it should be possible to add a target argument to $11 \mathrm{~b}$. However, it is possible that the two verb types involve different predicates, one of which allows targets and one of which does not. For example, if we analyzed frighten verbs as caused states and fear verbs as a form of mental possession, then we might attribute the target argument to the mental possession predicate, which is absent in the case of the frighten verbs. This account might predict that the experiencers of fear verbs would be seen more as owners of their emotions and that these emotions would be construed of as more mental and less physical than those encoded in frighten verbs. At the moment, no studies have attempted to directly test which verbs, at a representational level, involve the same semantic features. To our knowledge, there are no well-developed methods for doing so (e.g., some form of priming). The present work highlights the importance of developing these methods. 


\section{References}

Ambridge, B., \& Lieven, E. V. M. (in press). A Constructivist Account. In B. MacWhinney \& W. O’Grady (Eds.). Emergentist Perspectives on Child Language Acquisition.

Ambridge, B., \& Lieven, E. V. M. (2011). Child Language Acquisition: Contrasting Theoretical Approaches. Cambridge, UK: Cambridge University Press.

Ambridge, B., Pine, J. M., \& Rowland, C. F. (2012). Semantics versus statistics in the retreat from locative overgeneralization errors. Cognition.

Ambridge, B., Pine, J. M., \& Rowland, C. F. (2011). Children use verb semantics to retreat from overgeneralization errors: A novel verb grammaticality judgment study. Cognitive Linguistics, $22(2), 303-323$.

Ambridge, B., Pine, J. M., Rowland, C. F., \& Chang, F. (2012). The roles of verb semantics, entrenchment and morphophonology in the retreat from dative argument structure overgeneralization errors. Language.

Ambridge, B., Pine, J. M., Rowland, C. F., Chang, F., \& Bidgood, A. (2013). The retreat from overgeneralization in child language acquisition: Word learning, morphology, and verb argument structure. Wiley Interdisciplinary Reviews: Cognitive Science, 4, 47-62.

Ambridge, B., Pine, J. M., Rowland, C. F., Jones, R. L., \& Clark, V. (2009). A semantics-based approach to the 'no negative-evidence' problem. Cognitive Science, 33(7), 1301-1316.

Ambridge, B., Pine, J. M., Rowland, C. F., \& Young, C. R. (2008). The effect of verb semantic class and verb frequency (entrenchment) on children's and adults' graded judgments of argument-structure overgeneralization errors. Cognition, 106, 87-129.

Arad, M. (1998). Psych-notes. UCL Working Papers in Linguistics, London, UK: Department of Phonetics and Linguistics, University College of London, pp. 203-223.

Baker, M.C. (1988). Incorporation: A Theory of Grammatical Function Changing. Chicago, IL: 
University of Chicago Press.

Baillargeon, R., \& Carey, S. (2012). Core cognition and beyond: The acquisition of physical and numerical knowledge. In S. Pauen (Ed.), Early Childhood Development and Later Outcome (pp. 33-65). Cambridge: Cambridge University Press.

Baker, M.C., 1988. Incorporation: A Theory of Grammatical Function Changing. University of Chicago Press, Chicago.

Barner, D., Li, P., \& Snedeker, J. (2010). Words as windows to thought: The case of object representation. Current Directions in Psychological Science, 19, 195-200.

Bates, E., Bretherton, I., \& Snyder, L. (1988). From first words to grammar: Individual differences and dissociable mechanisms. Cambridge, MA: C’ University Press.

Beavers, J. (2011). An aspectual analysis of ditransitive verbs of caused possession in English. Journal of Semantics, 28(1), 1-54.

Belletti, A., \& Rizzi, L. (1988). Affect verbs and theta-theory. Natural Language \& Linguistic Theory, $6,291-352$.

Bellinger, D., \& Gleason, J. (1982). Sex differences in parental directives to young children. Journal of Sex Roles, 8, 1123-1139.

Berko Gleason, J. (1958). The child's learning of English morphology. Word, 14, 150-177.

Bernstein, N. (1984). Patterns of vowel modification in motherese. Journal of Child Language, 11, 557578.

Bialy, A. (2005). Polish Psychological Verbs at the Lexicon-Syntax Interface in Cross-Linguistic Perspective. Frankfurt: Peter Lang.

Bliss, L. (1988). The development of modals. The Journal of Applied Developmental Psychology, 9, 253-261. 
Bloom, L. (1973). One word at a time: The use of single-word utterances before syntax. The Hague: Mouton.

Bloom, L., Hood, L., \& Lightbown, P. (1974). Imitation in language development: If, when and why. Cognitive Psychology, 6, 380-420.

Bloom, L., Lightbown, P., \& Hood, L. (1975). Structure and variation in child language. Monographs of the Society for Research in Child Development, 40.

Bohannon, J. N., \& Marquis, A. L. (1977). Children's control of adult speech. Child Development, 48, 1002-1008.

Bowerman, M. (1987). The 'No Negative Evidence' problem: How do children avoid constructing an overly general grammar? J. A. Hawkins (Ed.), Explaining Language Universals (pp. 73-101). Oxford, UK: Basil Blackwell.

Bowerman, M. (1988). The "no negative evidence" problem: How do children avoid constructing an overly general grammar? J. A. Hawkins (Ed.), Explaining language universals (pp. 73-101). Oxford: Blackwell.

Bowerman, M. (1990). Mapping thematic roles onto syntactic functions: Are children helped by innate linking rules? Linguistics, 28, 1253-1289.

Boyd, J. K. \& Goldberg, A. E. (2011). Learning what NOT to say: The role of statistical preemption and categorization in A-adjective production. Language, 85, 55-83.

Braine, M. D. S. (1971). On two types of models of the internalization of grammars. D. I. Slobin (Ed.), The Ontogensisis of Grammar (pp. 153-186). New York, NY: Academic Press.

Braine, M. D. S., \& Brooks, P. (1995). Verb argument structure and the problem of avoiding an overgeneral grammar. M. Tomasello \& W. E. Merriman, Beyond Names for Things (pp. 353376). Hillsdale, NJ: Lawrence Earlbaum. 
Brent, M. R., \& Siskin, J. M. (2001). The role of exposure to isolated words in early vocabulary development. Cognition, 81, 31-44.

Brown, R. (1957). Linguistic determinism and the part of speech. Journal of Abnormal and Social Psychology, 55(1), 1-5.

Brown, R. (1973). A First Language: The Early Stages. Cambridge, MA: Harvard University Press.

Cardona, G. (1965). A Gujarati Reference Grammar, Philadelphia, PA: University of Pennsylvania Press.

Carey, S. (2009). The Origin of Concepts. New York: Oxford University Press.

Carlson, G. N. (1977). Reference to kinds in English. Ph.D. thesis, University of Massachusetts, Amherst.

Cartwright, T. A., \& Brent, M. R. (1997). Syntactic categorization in early language acquisition: Formalizing the role of distributional analysis. Cognition, 63, 121-170.

Chater, N. \& Christiansen, M. H. (2010). Language acquisition meets language evolution. Cognitive Science, 34, 1131-1157.

Christiansen, M. H., Onnis, L., \& Hockema, S. A. (2009). The secret is in the sound: From unsegmented speech to lexical categories. Developmental Science, 12(3), 388-395.

Clark, E. V. (2004). How language acquisition builds on cognitive development. Trends in Cognitive Sciences, 8(10), 472-478.

Coppola, M. \& Newport, E. L. (2005). Grammatical subjects in home sign: Abstract linguistic structure in adult primary gesture systems without linguistic input. Proceedings of the National Academy of Sciences, 102(52), 19249-19253.

Croft, W. (1986). Surface subject choice of mental verbs. Paper presented at the Annual Meeting of the Linguistic Society of America, New York.

Croft, W. (1993). Case marking and the semantics of mental verbs, in J. Pustejovsky (Ed.), Semantics 
and the Lexicon. Dordrecht: Kluwer Academic.

Croft, W. (2001). Radical construction grammar: Syntactic theory in typological perspective. Oxford: Oxford University Press.

Croft, W. (2012). Verbs: Aspect and Argument Structure. Oxford, UK: Oxford University Press.

Culicover, P. W., \& Jackendoff, R. (2005). Simpler Syntax. Oxford, UK: Oxford University Press.

Demetras, M. (1989a). Changes in parents' conversational responses: A function of gram $\neg$ matical development. Paper presented at ASHA, St. Louis, MO.

Demetras, M. (1989b). Working parents conversational responses to their two-year-old sons. Working paper. University of Arizona.

Demetras, M., Post, K., \& Snow, C. (1986). Feedback to first-language learners. Journal of Child Language, 13, 275-292.

Demuth, K., Culbertson, J., \& Alter, J. (2006). Word-minimality, epenthesis, and coda licensing in the acquisition of English. Language \& Speech, 49, 137-174.

Dickinson, D. K., \& Tabors, P. O. (Eds.). (2001). Beginning literacy with language: Young children learning at home and school. Baltimore: Paul Brookes Publishing.

Dittmar, M., Abbot-Smith, K., Lieven, E., \& Tomasello, M. (2011). Children ages 2;1 use transitive syntax to make a semantic-role interpretation in a pointing task. Journal of Child Language 38, 1109-1123. doi: 10.1017/S0305000910000747

Dixon, R. M. W. (1994). Ergativity. Cambridge, UK: Cambridge University Press.

Dowty, D. R. (1991). Thematic proto-roles and argument selection, Language, 67, 547-619.

Dryer, M. S., \& Haspelmath, M., Eds. (2013). The World Atlas of Language Strutures Online. Leipzig: Max Planck Institute for Evolutionary Anthropology.

Ekman, P. (1992). An argument for basic emotions. Cognition and Emotion, 6, 169-200.

Fernandes, K. J., Marcus, G. F., Di Nubila, J. A. D., \& Vouloumanos, A. (2006). From semantics to 
syntax and back again: Argument structure in the third year of life. Cognition 100, B10-B20. doi: 10.1016/j.cognition.2005.08.003

Ferreira, F. (1994). Choice of passive voice is affected by verb type and animacy. Journal of Memory and Language, 33, 715-736.

Fisher, C. (2002). The role of abstract syntactic knowledge in language acquisition: A reply to Tomasello (2000). Cognition, 82, 259-278.

Fisher, C., Gertner, Y., Scott, R. M., \& Yuan, S. (2010). Syntactic Boostrapping. Wiley Interdisciplinary Reviews: Cognitive Science, 1, 143-149.

Fodor, J. A. (1970). Three reasons for not deriving kill from cause to die. Linguistic Inquiry, 1, 429-38.

Foley, W. A., \& van Valin, R. D. (1984). Functional Syntax and Universal Grammar, Cambridge, UK: Cambridge University Press.

Gentner, D., \& Boroditsky, L. (2001). Individuation, relational relativity and early word learning. In M. Bowerman \& S. Levinson (Eds.), Language Acquisition and Conceptual Development. Cambridge, England: Cambridge University Press.

Gibson, E., Piantadosi, S. T., Brink, K., Bergen, L., Lim, E., \& Saxe, R. (2013). A noisy-channel account of crosslinguistic word order variation. Psychological Science, 4(7), 1079-88.

Gleitman, L. (1990). The structural sources of verb meanings. Language Acquisition, 1, 3-55.

Gleitman, L. R., Cassidy, K., Papafragou, A., Nappa, R., \& Trueswell, J. T. (2005). Hard words. Journal of Language Learning and Development, 1(1), 23-64.

Gleitman, L. R., \& Newport, E. L. (1995). The invention of language by children: Environmental and biological influences on the acquisition of language. In L. R. Gleitman \& M. Liberman (Eds.), Language (Vol. 1). An invitation to Cognitive Science (pp. 1-24). Cambridge, MIT Press.

Goldberg, A. E. (1995). Constructions: A Construction Grammar Approach to Argument Structure. Stanford, CA: Center for the Study of language and Information Publications. 
Goldberg, A. E. (2006). Constructions at Work. Oxford, UK: Oxford University Press.

Goldberg, A. E. (2013). Argument structure constructions versus lexical rules or derivational verb templates. Mind \& Language, 28(4), 435-465.

Goldin-Meadow, S. \& Mylander, C. (1990). Beyond the input given: The child's role in the acquisition of language. Language, 66(2), 323-355.

Grafmiller, J. (2013). The semantis of syntactic choice: An analysis of English emotion verbs (Doctoral dissertation). Stanford University, Palo Alto, CA.

Grimshaw, J. (1981). Form, function, and the language acquisition device. In C. L. Baker \& J. J. McCarthy, eds., The logical problem of language acquisition. Cambridge, MA: MIT Press.

Grimshaw, J. (1990). Argument Structure. Cambridge, MA: The MIT Press.

Gropen, J., Pinker, S., Hollander, M., \& Goldberg, R. (1991a). Affectedness and direct objects: The role of lexical semantics in the acquisition of verb argument structure. Cognition, 41, 153-195.

Gropen, J., Pinker, S., Holander, M., \& Goldberg, R. (1991b). Syntax and semantics in the acquisition of locative verbs. Journal of Child Language, 18, 115-151.

Gropen, J., Pinker, S., Hollander, M., Goldberg, R., \& Wilson, R. (1989). The learnability and acquisition of the dative alternation in English. Language, 65, 203-257.

Haggerty, L. (1929). What a two-and-one-half-year-old child said in one day. Journal of Genetic Psychology, 38, 75-100.

Hall, W. S., Nagy, W. E., \& Linn, R. (1984). Spoken words: Effects of situation and social group on oral word usage and frequency. Hillsdale, NJ: Erlbaum.

Hall, W. S., Nagy, W. E., \& Nottenburg, G. (1981). Situational variation in the use of internal state words. Champaign, IL: University of Illinois. 
Hartshorne, Joshua K., Amanda Pogue, and Jesse Snedeker (2015). Love is hard to understand: The relationship between transitivity and caused events in the acquisition of emotion verbs. Journal of Child Language, 42, 467-504.

Hartshorne, Joshua K. \& Adena Schachner (2012). Tracking replicability as a method of postpublication open evaluation. Frontiers in Computational Neuroscience, 6:8. Doi:10.3389/fncom.2012.00008

Hartshorne, J. K., \& Snedeker, J. (2013). Emotion verbs and the problem of overgeneralization. Presented at BUCLD 38, Boston, MA.

Higginson, R. P. (1985). Fixing-assimilation in language acquisition. Washington State University. Jackendoff, R. (1990). Semantic Structures. Cambridge, MA: The MIT Press.

Kline, M., \& Demuth, K. (2014). Syntactic generalization with novel intransitive verbs. Journal of Child Language, 41(3), 543-574. doi: 10.1017/S0305000913000068

Kipper, K., Korhonen, A., Ryant, N., \& Palmer, M. (2008). A large-scale classification of English verbs. Language Resources and Evaluation Journal, 42, 21-40.

Kuczaj, S. (1977). The acquisition of regular and irregular past tense forms. Journal of Verbal Learning and Verbal Behavior, 16, 589-600.

Lakusta, L., Wagner, L., O’Hearn, K., \& Landau, B. (2007). Conceptual foundations of spatial language: Evidence for a goal bias in infants. Language Learning and Development, 3(3), 179-197.

Landau, I. (2010). The Locative Syntax of Experiencers. Cambridge, MA: The MIT Press.

Levin, B. (1983). On the nature of ergativity. Ph.D. dissertation, MIT.

Levin, B. (1993). English Verb Classes and Alternations: A Preliminary Investigation. Chicago, IL: University of Chicago Press.

Levin, B., \& Grafmiller, J. (2013). Do you always fear what frightens you? In T. H. King \& V. de Paiva (Eds)., From quirky case to representing space: Papers in honor of Annie Zaenen. Stanford, CA: 
CSLI Publications.

Levin, B., \& Rappaport Hovav, M. (2005). Argument Realization. Research Surveys in Linguistics Series. Cambridge, UK: Cambridge University Press.

Li, P., Dunham, Y., \& Carey, S. (2009). Of substance: The nature of language effects on construal. Cognitive Psychology, 58, 487-524

MacDonald, J. L., Bock, K., \& Kelly, M. H. (1993). Word order and world order: Semantic, phonological, and metrical determinants of serial position. Cognitive Psychology, 25(2), 188230.

MacWhinney, B. (1977). Starting points. Language, 53, 152-168.

MacWhinney, B. (2000). The CHILDES Project: Tools for Analyzing Talk, 3rd ed. Mahwah, NJ: Lawrence Erlbaum Associates.

Marantz, A.P. (1982). On the acquisition of grammatical relations. Linguistische Berichte: Linguistik als Kognitive Wissenschaft, 80/82, 32-69.

Mazurkewich, I., \& White, L. (1984). The acquisition of the dative alternation: Unlearning overgeneralizations. Cognition, 16, 261-83.

Menn, L., \& Feldman, A. (2001). Commentary on 'Filler syllables: what is their status in emerging grammar?' by Ann Peters. Journal of Child Language, 28, 269-271.

Moens, M., \& Steedman, M. (1988). Temporal ontology and temporal reference. Computational Linguistics, 14(2), 15-28.

Monaghan, P., Chater, N., \& Christiansen, M. H. (2005). The differential role of phonological and distributional cues in grammatical categorization. Cognition, 96, 143-182.

Montrul, S. (2001). First-language-constrained variability in the second-langauge acquisition of argument-structure-changing morphology with causative verbs. Second Language Research, 17, 144-194. 
Morisset, C. E., Barnard, K. E., Greenberg, M. T., Booth, C. L., \& Spieker, S. J. (1990). Environmental infuence on early language development: The context of social risk. Development and Psychopathology, 2, 127-149.

Ninio, A., Snow, C., Pan, B., \& Rollins, P. (1994). Classifying communicative act in children's interactions. Journal of Communications Disorders, 27, 157-188.

Noble, C. H., Rowland, C. F. \& Pine, J. J. (2011). Comprehension of argument structure and semantic roles: Evidence from English-learning children and the forced-choice pointing paradigm. Cognitive Science 35, 963-982. doi:10.1111/j.1551-6709.2011.01175.x

Oehrle, R. T. (1976). The grammatical status of the English dative alternation. Ph.D. dissertation, MIT. Paczynski, M., \& Kuperberg, G. R. (2011) Electrophysiological evidence for use of the animacy hierarchy, but not thematic role assignment, during verb argument processing. Language and Cognitive Processes, 26(9), 1402-1456.

Pesetsky, D. (1995). Zero Syntax: Experiencers and Cascades. Cambridge, MA: The MIT Press.

Piantadosi, S. T., Tily, H., \& Gibson, E. (2011). Word lengths are optimized for efficient communication. Proceedings of the National Academy of Sciences, 108, 3526-3529.

Pinango, M. M. (2000). Cannonicity in Broca's sentence comprehension: The case of psychological verbs. In Grodzinsky, Y., (Ed.), Language and the Brain: Representing and Processing. San Diego, CA: Academic Press, 327-350.

Pinker, S. (1984). Language Learnability and Language Development. Cambridge, MA: Harvard University Press.

Pinker, S. (1989). Learnability and Cognition. Cambridge, MA: The MIT Press.

Post, K. (1992). The language learning environment of laterborns in a rural Florida community. Harvard University. 
Post, K. (1994). Negative evidence. In J. Sokolov \& C. Snow (Eds.), Handbook of Research in Language Development using CHILDES). Hillsdale, NJ: Lawrence Erlbaum Associates.

Pylkkanen, L. (1999). On stativity and causation. In C. Tenny \& J. Pustejovsky (Eds.), Events and Grammatical Objects. Stanford, CA: CSLI Publications.

Rappaport, M., \& Levin, B. (1985). A case study in lexical analysis: The locative alternation. Unpublished manuscript, MIT Center for Cognitive Science.

Rappaport Hovav, Malka \& Beth Levin 1998a. Morphology and lexical semantics. In: A. Spencer \& A. Zwicky (Eds.). The Handbook of Morphology. Oxford, UK: Blackwell, 248-271.

Rappaport, M., \& Levin, B. (1988). What to do with theta-roles. In Wilkins, W., ed., Thematic relations. New York: Academic Press.

Rozwadowska, B. (1992). Thematic Constraints on Selected Constructions in English and Polish. Anglica Wratislaviensia XX. Warsaw: Wydawnictwo Uniwersytetu Wroclawskiego.

Russell, J. A. (1980). A circumplex model of affex. Journal of Personality and Social Psychology, 39(6), 1161-1178.

Sachs, J. (1983). Talking about the there and then: The emergence of displaced reference in parent-child discourse. In K. E. Nelson (Ed.), Children's Language): Hillsdale, NJ.

Sato, Y. (2003). Japanese learners' linking problems with English psych verbs. Reading Working Papers in Linguistics, 7, 125-144.

Soderstrom, M., Blossom, M., Foygel, R., \& Morgan, J. L. (2008). Acoustical cues and grammatical units in speech of two preverbal infants. Journal of Child Language, 35, 869-902.

Spelke, E. S., \& Kinzler, K. D. (2007). Core knowledge. Developmental Science, 10, 89-96.

Stine, E. L., \& Bohannon, J. N. (1983). Imitations, interactions, and language acquisition. Journal of Child Language, 10, 589-603.

Suppes, P. (1974). The semantics of children's language. American Psychologist, 29, 103-114. 
Talmy, L. (1985). Lexicalization rules: Semantic structure in lexical forms. In T. Shopen (Ed.), Language Typology and Syntactic Description 3: Grammatical Categories and the Lexicon (pp. 57-149). Cambridge, UK: Cambridge University Press.

Talmy L. (2000). Toward a Cognitive Semantics. Cambridge, MA: The MIT Press.

Tenny, C. (1994). Aspectual Roles and the Syntax-Semantics Interface. Dordrecht: Kluwer.

Thompson, C., \& Lee, M. (2009). Psych verbs production and comprehension in agrammatic Broca's aphasia. Journal of Neurolinguistics, 22, 354-369.

Tomasello, M. (1992). First Verbs: A Case Study of Early Grammatical Development. Cambridge, UK: Cambridge University Press.

Tomasello, M. (2003). Constructing a language: A usage-based theory of language acquisition. Cambridge, MA: Harvard University Press.

Tsujimura, N. (1996). Introduction to Japanese Linguistics. Malden, MA:Wiley-Blackwell.

Valian, V. (1991). Syntactic subjects in the early speech of American and Italian children. Cognition, 40, 21-81.

Van Gelderen, E. (in press). Changes in psych-verbs: A reanalysis of Little v. Journal of Catalan Linguistics.

Van Houten, L. (1986). Role of maternal input in the acquisition process: The communicative strategies of adolescent and older mothers with their language learning children, Boston University Conference on Language Development). Boston, MA.

Wade, R. (2011). A Comprehensive Russian Grammar. Singapore: John Wiley \& Sons Ltd.

Warren-Leubecker, A. (1982). Sex differences in speech to children. Georgia Institute of Technology.

Warren-Leubecker, A., \& Bohannon, J. N. (1984). Intonation patterns in child-directed speech: Motherfather speech. Child Development, 55, 1379-1385. 
Weckerly J, Kutas M. An electrophysiological analysis of animacy effects in the processing of object relative sentences. Psychophysiology.1999;36:559 - 570

Weist, R. M., Pawlak, A., \& Hoffman, K. (2009). Finiteness systems and lexical aspect in child Polish and English. Linguistics, 47, 1321-1350.

Weist, R. M., \& Zevenbergen, A. (2008). Autobiographical memory and past time reference. Language Learning and Development, 4, 291-308.

White, L., Brown, C., Bruhn-Garavito, J., Chen, D., Hirakawa, M., \& Montrul, S. (1998). Psych verbs in second language acquisition. In Klein, E. \& Martohardjono, G., (Eds.), The Development of Second Langauge Grammars: A Generative Approach. Philadelphia, PH: Bartholomew Benjamins, 171-196. 